[Aus dem Kgl. Institut für Infektionskrankheiten „Robert Koch“ zu Berlin.] (Direktor: Gel. Med.-Rat Prof. Dr. Neufeld.)

\title{
Über Händedesinfektion und Händereinigung in ihrer Bedeutung zur Verhütung von Krankheitsubertragungen. Von
}

Dr. 0. Schiemann und Dr. Hans Landau, Assistenten an Institut.

\section{Einleitung. Frühere Untersuchungen. Versuchstechnik.}

Bekanntlich haben die Beobachtungen iiber die Verbreitung der Infektionskrankheiten mehr und mehr zu der Utberzeugung geführt, daß der infizierte Mensch - der Kranke und der Bazillenträger - im Mittelpunkt aller unserer Maßnahmen stehen muß, daß die Utbertragung von Person zu Person fast immer die Hauptgefahr darstellt, während die Verbreitung durch leblose Gegenstände demgegenüber weit zurücktritt. Nun ist aber die infizierte Hand bei den Krankheiten, deren Erseger durch Stuhl und Urin ausgesch eden werden, weitaus das wichtigste Medium der Ubertragung; aber auch bei Diphtherie, Tuberkulose und anderen Krankheiten, deren Verbreitung vorwiegend dureh ausgehustete Tröpfehen geschieht, spielen daneben infizierte Hände zweifellos eine Rolle.

Dementsprechend müssen wir auch die Desinfektion der infizierten Hand für viel wichtiger ansehen, als die Desinfektion der Wohnung, der Wäsche usw., zumal die Ansteckung durch Wäsche, infizierte Fußböden, Steckbecken $\mathbf{u}$. dgl. in der Regel wiederum erst durch Vermittlung beschmutzter Finger erfolgt. Ebenso werden viele der zahlreichen Infektionen durch Nahrungsmittel im Grunde durch schmutzige Finger vermittelt. Die Bedeutung der Händereinigung und Händedesinfektion für die Verbreitung der Seuchen kann daher nicht leicht hoch genug veranschlagt werden. Dieser Bedeutung entspricht jedoch nicht das, was in den jetzt geltenden Desinfektionsanweisungen und Nerkblättern darüber gesagt ist. 
Aber auch experimentell ist im Vergleiche mit der Wohnungsdesinfektion und der Desinfektion von Wäsche, Kleidern, Betten usw. die Desinfektion infizierter Hände im obigen Sinne (also abgesehen von der chirurgischen Händedesinfektion) verhältnismäßig wenig bęarbeitet worden. Im nachstehenden soll daher eine gröBere Anzahl solcher Versuche, die im Institut im Verlaufe der letzten Jahre ausgeführt worden sind, mitgeteilt werden.

Unsere Versuche bilden eine Fortsetzung der von Börnstein mitgeteilten; wir verweisen daher auf diese Arbeit sowohl bezüglich der einschlägigen Literatur (Seitz, Flügge, Speck, Igersheimer, Gäthgens) als auch bezüglich der Versuchsanordnung. Wir haben ebenso wie Börnstein in der Regel als Testobjekt zur künstlichen Infektion der Hand Colibazillen benutzt, die sich beziiglich ihrer Resistenz gegen Antiseptika ähnlich wie Typhus und Ruhr verhalten. Wichtig erscheint uns bezüglich der Versuchstechnik besonders die-Abimpfung in flüssigen Drigalski-ConradiAgar. Es ist das eine sehr empfindliche Prüfung, die auch mehr als andere Methoden den praktischen Verhältnissen entspricht; sie ergibt sicherere und zahlenmäßig besser vergleichbare Resultate als z. B. das Abreiben mit Schwämmchen oder Abkratzen mit Hölzchen, die dann auf die Oberfläche von Platten ausgestrichen oder in Bouillon angereichert werden. In letzterem Fall erhält man natürlich gar keine quantitativen Ergebnisse; für die Praxis ist es aber sehr wichtig, zu wissen, ob von den aufgebrachten Bakterien nach vollendeter Desinfektion etwa 100 oder 1000 oder nur ganz vereinzelte von den Händen wieder abgegeben werden. Andererseits haben wir nur an den Keimen Interesse, die von den Fingern nach außen abgegeben werden, nicht an denen, die sich vielleicht nur gewaltsam und mit der oberflächlichen Hautschicht zusammen entfernen lassen; daher ist eine. Versuchsanordnung, wobei die Unternagelräume mit NägeIn oder Holzstuickchen ausgekratzt und davon nach $\mathrm{Paul}$ und Sarweys Vorgang nach Abschütteln des Materials Platten gegossen werden, für unscre Zwecke wenig gecignet. Wir haben aber dic von uns durchweg benutzte Methode nach Schumburg mit der Entnahme nach Paul ind Sarwey verglichen; dabei ergab die letztere Methode nicht nur ungleichmäßigere Resultate, sondern auch durchschnittlich viel geringere Zahlen (vgl. Tab. 1).

In den früheren Arbeiten über Händedesinfektion ist die Einbettung der Bakterien in Fett- und Schmutzschichten oft erörtert worden und man hat darin sogar den Hauptgrund gesucht, weshalb die Desinfektion der Hände so schwierig ist. Nach unseren Versuchen halten wir diese Anschaunng, nicht nur was die chirurgisehề Desinfektion, sondern was auch die Desinfektion am Krankenbette betrifft, für.irrig. Sichtbare oberflächliche Schmutzschichten sind verhältnismäBig leicht zu desinfizieren; was 


\section{Tabelle 1.}

Vergleich verschiedener Methoden der Keimentnahme an mit Coli stark infizierten und mit verschiedenen Mitteln desinfizierten Händen.

\begin{tabular}{|c|c|c|c|c|c|c|c|c|c|c|}
\hline \multirow{3}{*}{$\begin{array}{l}\text { Entnahme nach Desinfektion mit: } \\
\text { Versuch Nummer . } \\
\text { Schumburgsche Methode }\end{array}$} & \multicolumn{3}{|c|}{$\begin{array}{r}21 / 2 \% \\
\beta \text {-Lysol }\end{array}$} & \multicolumn{2}{|c|}{$\begin{array}{l}80 \% \\
\text { Seifol }\end{array}$} & \multicolumn{3}{|c|}{$\begin{array}{c}10 \% \\
\text { Sagrotan }\end{array}$} & \multicolumn{2}{|c|}{$\begin{array}{c}25 \% \\
\text { Sagrotan }\end{array}$} \\
\hline & 1 & 2 & .3 & 1 & 2 & 1 & 2 & 3 & 1 & 2. \\
\hline & $\infty$ & 300 & 1000 & 350 & 200 & 1500 & 150 & 0 & 50 & 10000 \\
\hline Paul u. Șarveysche Methode ${ }^{1}$ & 45 & 250 & 500 & 100 & 0 & 100 & 0 & 5 & 0 & 5000 \\
\hline
\end{tabular}

dic Desinfektion - der Hand zu einer so überaus schwierigen, bisher nicht vollkommen lösbaren Aufgabe macht, ist nicht die Einbettung der Bakterien in Fett oder Schmutz, sondern ihre versteckte Lage in engen, blind endigenden Gängen und Spalten der Haut. Die normalen Keime der Haut liegen zum größten Teil von vornherein tief in den Hautspalten und Jrüsenausführungegängen, in denen sio sich dauernd vermehren; aber auch Bakterien, die man künstlich in einem Tropfen Kochsalzlösung auf die Haut bringt, dringen offenbar zum Teil schnell bis in die Tiefen der feinsten Hautspalten ein.

Für unumgänglich notwendig halten wir es, stets zahlreiche Versuche mit demselben Desinfektionsverfahren zu machen, um die individuellen Unterschiede der Hände, die wechselnde Beschaffenheit der zur Infektion benutzten Bakterion sowie andere Zufälligkeiten, die bei derartigen Versuchen unvermeidlich sind, nach Möglichkeit auszuschalten.

Bei der großon Zahl der Versuche haben wir davon abgesehen, die Hände jedesmal mit Fäzes zu beschmutzen, sondern statt dessen in der Regel Coliabschwemmungen in Bouillon oder Kochsalzlösung genommen. Immerhin haben wir dane ben bei den wichtigsten Desinfektionsverfahren eine Reihe von Versuchen mit sterilisierten Fäzes, denen künstlieh Coli zugesetzt war, gemacht. In einigen Versuchen ha ben wir anstatt Coli-auch Ruhrbazillen zur Infektion der Hände benutzt; in großem Maßstabe läßt sich aber aus begreiflichen Gründen eine solche Versuchsanordnung nicht verwenden.

Die im crsten Abschnitt unserer Arbeit mitgeteilten Versuche sind zum großen Teil noch in der Friedenszeit und im ersten Kriegsjalire angestellt worden, sie nehmen daher keine Rücksicht auf dic augenblickliche Knappheit an Chemikalien. Die Versuche schlossen sich an andere über chirurgische Händedesinfektion an; bei diesen letzteren hatten sich als weitaus beste Mittel Alkohol sowic ein Seifenalkohol mit etwa 80 Volum-

1 Hierbei wurde jedesmal nur ein Finger untersucht und die erhaltenen Zahlen mit s multipliziert, somit auf die ganze Hand berechnet. 
Prozent Alkohol bewährt. Um Verwechslungen mit dem nur 42 prozentigen Seifenspiritus des Arzneibuches zu vermeiden, der unseren Erfahrungen nach als Desinfektionsmittel wenig zweckmäßig ist, haben wir unseren etwa 80prozentigen, meist mit Rizinusseife hergestellten Seifenalkobol in. unserem Laboratorium als "Seifol" bezeichnet; wir behalten diese Bezeichnung in nachfolgendem bei. Auch was die Art der Anwendung der Alkoholpräparate betrifft, haben wir uns an die Erfabrungen bei der chirurgischen Händedesinfektion gehalten, indem wir bei Anwerdung größcrer Yengen (meist $20 \mathrm{ccm}$ ) die Hände mit einem damit getränkten Watteoder Gazebausch abricben, während kleine Mengen (meist $5 \mathrm{ccm}$ ) einfach zwischen den Händen verrieben wurden.

Die individuellen Verschiedenheiten der Hände spielen bei der kiunstlich infizierten Hand eine wichtige Rolle, wenn sie sich auch nicht in so hohem Grade bemerkbar machen, wie bei der "Tageshand". Beispiele dafür ergeben sich aus unseren Tabellen. Wir fanden, daß bei bestimmten Personen die Hände danernd verhältnismäßig leicht, bei anderen dagegen durchschnittlich schwerer zu desinfizieren waren. Durchaus irrig ist aber nach unserer Erfahrung die vielfach vertretene Ansicht, daß rauhe und rissige Hände zur zweiten, wohlgepflegte Hände zur ersten Gruppe gehören; es handelt sich nicht um grobe Risse und Rauhigkeiten, sondern um viel feinere, mit blobem Auge nicht wahrnehmbare Unterschiede im Bau zur Haut.

$\mathrm{Zu}$ der individuellen Verschiedenheit der Hände kommt als weitere Quelle für Unregelmäßigkeiten und Fehlschlüsse die wechselnde Resistenz der benutzten Kultur. Wie aus Vitroversuchen bekannt ist, kommen solche Untersehiede auch dann vor, wenn man dauernd mit demselben Colistamm und anscheinend demselben Nährboden arbeitet; wir haben nicht nur allmähliche Abschwächung, sondern auch ohne erkennbare Ursache plötzliche Resistenzsteigerung unserer Colikultur gesehen. Aus diesen Gründen wäre es u. E. verkehrt, solche Versuche etwa in der Weise anzustellen, daß eine Person immer das Mittel A, eine zweite das Nittel $B$ benutzt; ebenso unrichtig wäre es, an einem Tage sämtliche Versuchspersonen sich mit A, am nächsten Tage mit B desinfizieren zu lassen. Die beste Versuchsanordnung ist folgende: will man z. B. 4 verschiedene Mittel vergleichen, so nimmt man 4 (oder 8) Versuchspersonen, die 8 (bzw. 4) Tage lang, täglich wechselnd, die 4 Mittel benutzen; dann erhält man für jedes Mittel 16 Versuche, bei denen die Fehlerquellen, die in der verschiedenen Beschaffenheit der Hände und der wechselnden Resistenz der Bakterien liegen, nach Möglichkeit gleichmäßig sich verteilen. Eine derartige Versuchsanordnung ist besonders damn erforderlich, wenn es sich 
um einen Vergleich von Mitteln handelt, die einander in ihrer Wirkung nahestehen. Da wir aber diese Methode erst im Verlauf unserer Untersuchungen als die beste erprobt haben, so ist bei einem Teil der nachstehenden Versuche, insbesondere bei den Versuchen der Tabellen 2 bis 4 , ein so regelmäßiger Wechsel der beteiligten Personen nicht vorgenommien worden. In allen Fällen haben wir aber jedes Verfahren an einer größeren Zahl von Personen geprüft und darauf geachtet, daß die Ergebnisse nicht durch vorwiegende Beteiligung solcher Personen becinträchtigt wurden, deren Hände erfahrungsgemäß entweder besonders schwer oder besonders leicht zu desinfizieren waren. Ferner. haben wir immer mehrere Mittel am selben Tage nebeneinander geprüft. Außerdem haben wir niemals die Ergebnisse von zeitlich weit auseinanderliegenden Versuchen verglichen, da sichl erfahrungsgemäß dio Resistenz der benutzten Colistämme in Laufe der Zeit oft erheblich änderte. Wir glauben daher, daß die in den nachstehenden Tabellen zusammengefaßten Vorsuche untereinander, d. h. innerhalb einer Tabelle, wirklich vergleichbar sind, was bei Versuchen, die ohne Berücksichtigung der genannten Punkte gemacht wurclen, u. E. nicht der Fall ist.

Alle erwähnten Fehlerquellen machen sich nun um so mehr bemerkbar, je schwächer wirksam die benutzten Desinfektionsmittel sind; daher sind die Ergebnisse bei Sublimat gleichmäßiger, als \%. B. bei Kresolseife und Karbol. Daß man aber bei Händedesinfektionsversuchen niemals so genaue zallenmäbige Ergebnisse erwarten darf, wie man sie bei Desinfektionsversuchem in vitro erhalten kann, braucht wohl nicht eigens hervorgehoben we den.

\section{If. Versuche über Desinfektion künstlich mit Bakterium coli infizierter Hïnde.}

Wir geben zunächst in den nachstehenden Tabellen 2 bis 4 die Ergebnisse wieder, die wir in größeren Versuchsreihen an Händen, die mit Bakterium coli in verschieden starkem Grade infiziert waren, erhalten haben. Die Tabellen umfassen über 700 Einzelversuche (jede Hand als 1 Versuch gerechnet). Meist wurde derselbe Stamm, Coli II, benutzt.

\section{Versuchs anordnung.}

Die in den Tabellen 2 bis 4 wiedergegebenen Versuche wurden mit cirei verschieden starken Abschwemmungen von Colibazillen an einer großen Zah] (bis 30) Personen angestellt. Die Coliaufschwemmung wurce in cine Petrischale mit Fließpapierstreifen gegossen und die feuchten Streifen zwischen den Fingern geknetet, so daß sämtliche Fingerkuppen einschließlich der Unternagelräume infiziert wurden; bei den späteren Versuchen haben wir die 
Fingerkuppen meist ohne Papier mit 2 bis 4 Tropfen dcr Coliaufschwemmung infiziert. Nach Antrocknung erfolgte die Desinfektion bzw. Seifenwaschung; dann wurden die Hände mit fließendem Leitungswasser gründlich gespült und mit steriler Gaze getrocknet. Darauf wurde jede Hand $3 / 4$ Minute lang in einer Petrischale mit flüssigem Drigalskiagar durch stämmençe und reibende Bewegung der Fingcr ausgedrückt, dabei wurden die Unternagelräume mit dem Daumennagel besonders bearbeitet.- Vor der Dcsinfektion wurde mit 1 oder 2 Fingern einer Hand in gleicher Weise eine Drigalskiplatte infiziert. In der Regel wurden bei „starker Infektion" über 20000 Keime von einem Finger, d. h. über 100000 Keime von der Hand abgegeben. Bei der ,mittelstarken Infektion" schwankten die Zahlen um 2000 bis 5000 für die Hand, jedoch in einzelnen Fällen gingen sie bis auf einige 100 Keime herab. Bei der ",schwachen Infektion" schwankte die Keimabgabe zwischen 50 bis einige 100, doch waren hier die Unregelmäßigkeitcn größer. So mußten von 44 Versuchen mit, schwacher Infektion" 10 von der Beurteilung ausgeschlossen werden, weil die Probe vor der Desinfelstion 0 oder weniger als 10 Keime ergeben hatte. Es wurde daher darauf gesehen, daß bei der "schwachen und mittelstarken Infektion" möglichst jede Person eine solcho Vorprüfung vornahm, während bei starker Infektion es genügte, wenn eine oder zwei der am Versuche beteiligten Personen die Keimabgabe vor der Desinfektion prüfte. Um Zufälligkeiten auszuischalten und den Grad der Infektion stets zu kontrollieren, wurden nicht etwa an einem Tage nur gute, am anderen Tage schlecht wirksame Mittel geprüft, sondern die Auswahl wurde so getroffen, daß stets eins von den gutwirkenden Mitteln geprüft wurde. Die Beurteilung der Platten geschah durch Abschätzung der Zahl der gewachsenen Colikolonien, bis 100 Keime wurden meist gezäblt. Da die Hände ja schon vor der Infektion eine große Menge von eigenen Keimen enthalten, von denen allerdings nur ein kleiner Bruchteil auf Drigalskiagar auswächst, so mußte zwischen diesen und den Coljkolonien unterschieden werden. In der Regel zeigen Kokkenkolonien einen hellen Saum und tein blaßrötliches Zentrum. Ein roter Hof kann sich um sie ebenfalls bilden, doch jst er gewöhnlich nicht so intensiv rot wie der der Colikolonien, so daß in der Mehrzahl der Fälle. die Unterscheidung leicht gelingt. Andererseits kann jedoch mitunter die Säurebildung der Colikolonien bei starker Konkurrenz der Hand̉bakterien gehemmt sein. Bei spärlichen und zweifelhaften ticfliegenden Kolonien wurden diese mit der Nadel an die Oberfläche gebracht und erforderlichenfalls weiter untersucht. Da die Erkennung dcr Colikolonien besonders bei schwacher' Colinfektion gelegentlich größ $B$ re Schwierigkeiten macht, so haben wir in unseren späteren Versuchen durch Abreiben der Hände mit Alkohol vor der Infektion die störenden Handkeime beseitigt; diese Versuchsanordnung hat sich bei uns sehr gut bewährt.

\section{Tabelle 2.}

Vergleich der Wirkung verschiedener Verfahren zur Desinfektion stark infizierter Hände.

Die Alkoholpräparate wurden bis zur Verdunstung verrieben, alle übrigen Verfahren wurden 2 ' lang angewendet. 


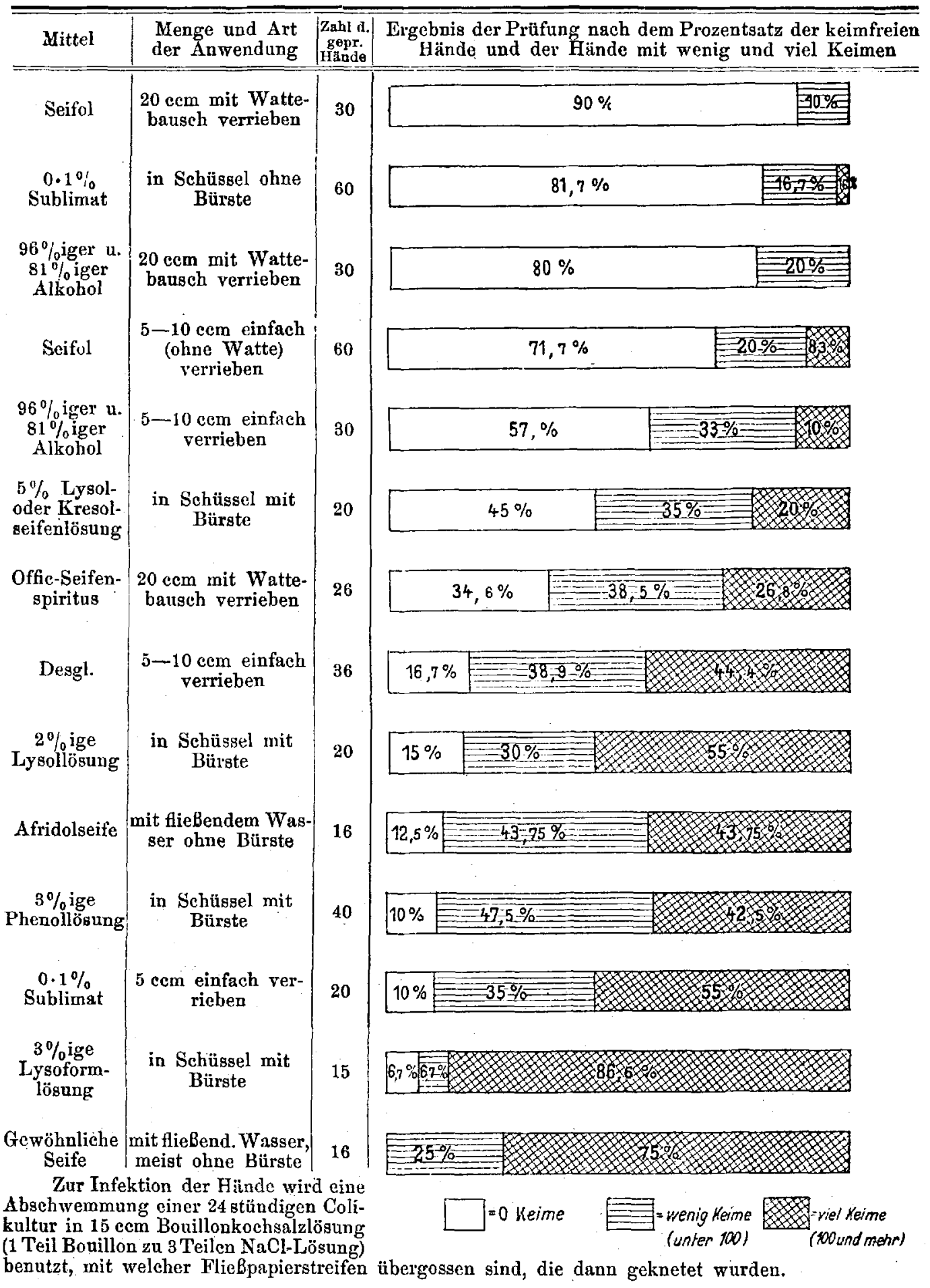


Tabelle 3.

Vergleich verschiedener Verfahren bei mittelstarker Infektion.

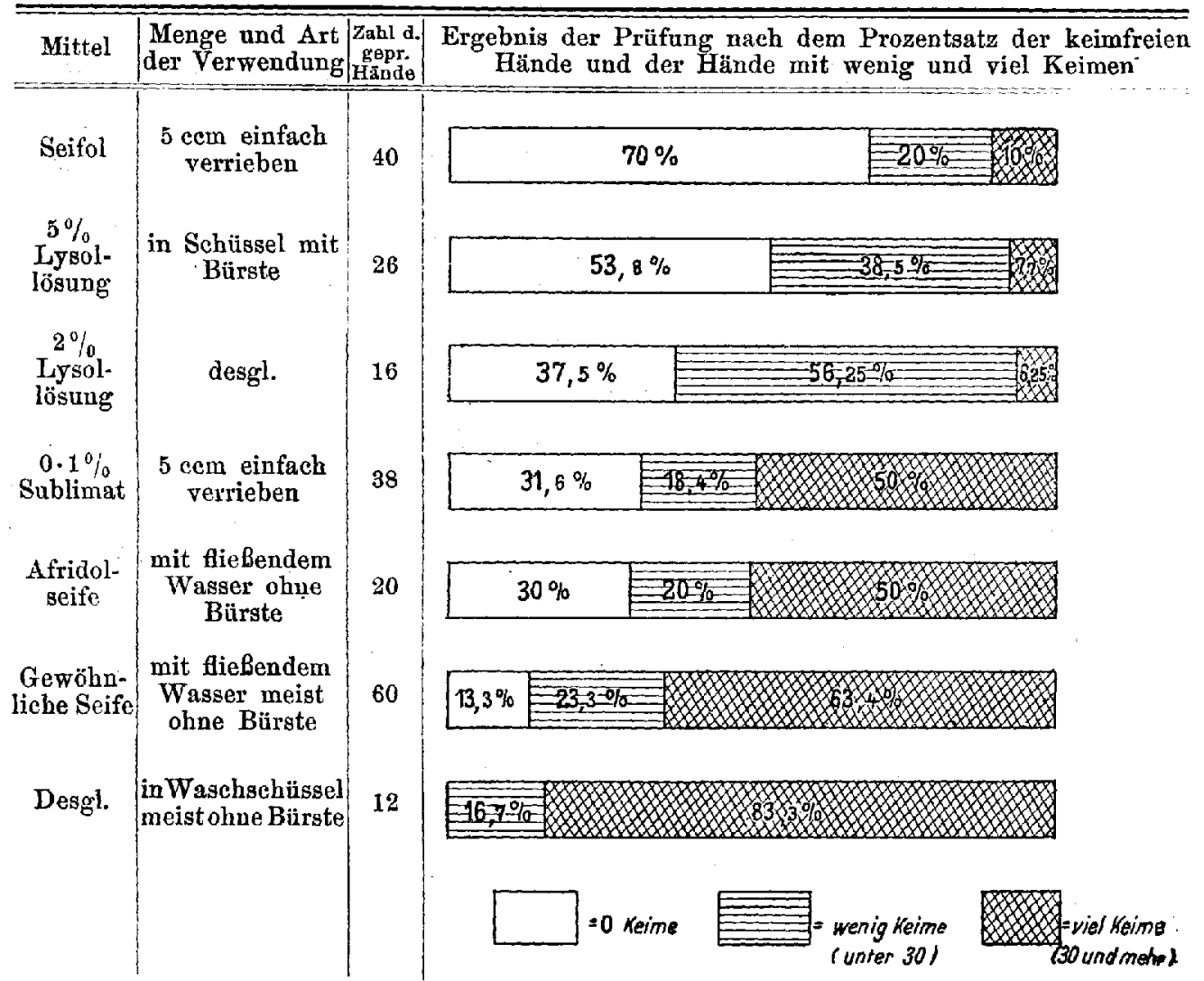
Infektion.

Die zur Infektion "benutzte Coli-Abschwemmung ist $100 \mathrm{mal}$ dünner als bei der starken

Wie schon hervorgehoben wurde, haben wir bei diesen Versuchen noch nicht alle vorhin erwähnten Kautelen angewendet; dafür, daß unsere Ergebnisse trotzdem als annähernd zuverlässig angesehen werden können, spricht aber auch der Umstand, daß sich bei den obigen drei Untersuchungsreihen fast genau die gleiche Reihenfolge der einzelnen Desinfektionsvertahren ergab.

Nach Tabb. 2 bis 4 erscheinen von den geprüften Verfahren die Desinfektion mit Seifol oder hochprozentigem Alkohol, in Mengen von etwa $20 \mathrm{ccm}$ mittels eines Wattebausches verrieben, sowie etwa $2 \mathrm{Mi}$ -

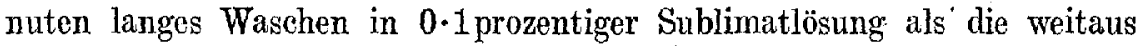
besten. 
Tabelle 4.

Vergleich verschiedener Verfahren bei schwacter Infektion.

Alle Verfahren werden $2^{\prime}$ lang angewendet.

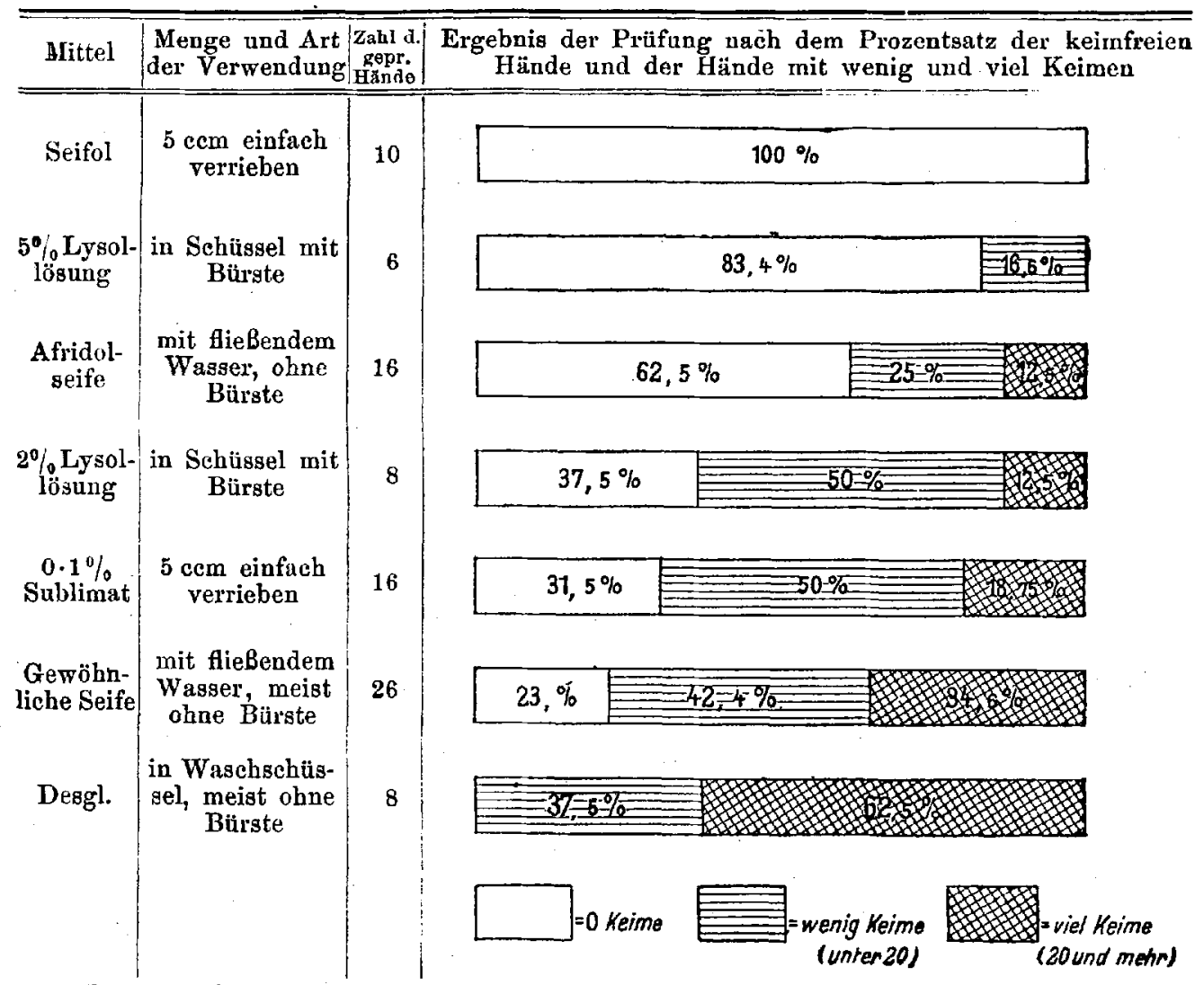

Die zur Infektion benutzte Colikulturaufachwemmung ist $1000 \mathrm{mal}$ dünner als bei „starker Infektion".

Seifol wirkte in diesen ebenso wie in anderen Versuchen mit Bact. coli noch etwas besser als Alkohol allein; da aber der Unterschied nicht grob ist, so wird es mehr von den praktischen. Verhältnissen abhängen, ob man Alkohol mit oder ohne Seifenzusatz anwenden will. Oft wird man, z. B. auch im Laboratorium, den Wunsch haben, zugleich eine Seifenwaschung vorzunehmen und es dann angenehm empfinden, daß man, nachdem man das Mittel anf der Haut verrieben hat, hinterher die Hände unter der Leitung abschäımt. Dazu kommt, daß von vielen Personen das Seifol an den Händen angenehmer empfunden wird, als der reine Alkohol. In anderen Fällen wieder wird man das Bedürfnis haben, den zur Desinfektion be- 
stimmten Alkohol vor anderweitiger Verwendung zu schützen und daher gern einen Zusatz von Seife machen. Wo dagegen kein Waschwasser und Handtuch zur Verfügung steht, oder wo die Desinfektion möglichst schnell geschehen soll, wird man reinen Alkohol, der schnell restlos verdunstet, vorziehen. In den Versuchen der Tabelle 2 und 3 ist fast ausschlieBlich der schon von Huntemüller und Eekard sowio von Börnstein benutzte Rizinusseifenalkohol mit 75 Gewichts- (= etwa 81. Volumen) Prozent Alkohol benutzt worden, der unseren Erfahrungen nach für die Hände angenehm und dauernd haltbar ist, während manche anderen Seifen im Laufe der Zeit ausfallen. Vermutlich werden auch andere Seifen als. Zusatz zum Alkohol geeignet sein. Jötten empfichlt einen Zusatz von Schmierseife.

Als reinen Alkohol haben wir in diesen Versuchen meist 96prozentigen benutzt. Er wirkte auf Bakterien, die in wässeriger Aufschwemmung kurz vorher auf die Hände gebracht waren, ausgezeichnet. Schon Hunte müller und Eckard haben aber darauf aufmerksam gemacht und nnsere unten (in Tabelle 23) wiedergegebenen Versuche an mit Fäzes infizierten Händen haben es bestätigt, daß so konzentrierter Alkohol in trockene bakterienhaltige Schichten von organischem Material nicht eindringt; daher ist in der Praxis, wo man immer mit solchen Verhältnissen rechnen muß, ausschließlich verdünnter, etwa 75 bis 80prozentiger Alkohol anzuwendeñ - es sei denn, daß die Hände zuvor mit Wasser gewaschen werden, was aber bei der Desinfektion am "Krankenbett zu widerraten ist (Flügge, Speck, Börnstein). Inmerhin wirkt aber, wie Tab. 13 zoigt, unter unseren Versuchsbed ngungen 80 prozentiger Alkohol doch schwächer als 96prozentiger; das ist wohl mit ein Grund, weshalb in unseren späteren Versuchsreihen die Desinfektion mit Alkohol im Vergleich mit der Sublimatdesinfektion wesentlich schlechtere Ergebnisse hatte. Daneben ist aber auch in Betracht zu ziehen, daß die Resistenz der später benutzten Colistämme eine größere war.

In den vorstehenden Versuchen ergaben Sublimatwaschungen annähernd dieselben Resultate, wie das Abreiben mit Alkohol.

Nun besteht aber ein wichtiger grundsätzlicher Unterschied zwischen der Sublimat- und der Alkoholdesinfektion. Während bei letzterer das Ausbleiben des Wachstums zweifellos wirklich auf Abtötung beruht ist das beim Sublimat nicht der Fall. Wir wissen vielmehr durch die Versuche von Geppert, vor allem aber durch die von Ottolenghi, daß bei genügender Nentralisierung des Sublimats durch Schwefelwasserstoff die Wirkung des Mittels 
als so schwach erscheint, daß selbst in 1prozentigen Lösungen Staphylokokken mehrere Stunden lang lebensfähig bleiben könnon.

Was uns für gewöbnlich als Abtötung erscheint, ist also zum großen Teil nur eine Entwicklungshemmung, die durch die starke Adsorption des Mittels seitens der Bakterien bewirkt wird. DaB das nicht nur für Desinfektionsverusche in vitro, sondern auch für die Händedesinfektion mit Sublimat gilt, daß also auch hier bei nachträglicher Neutralisierung durch Schwefelammonium zahlreiche Keime wieder zum Vorschein kommen, hat Speck bewiesen. Dasselbe zeigen unsere nachstehenden Versuche.

\section{Tabelle 5.}

Starke Infektion der Hände mit Bact. coli, danach 2 Minuten Waschen in 0.1 prozentiger Sublimatlösung, darauf Abspülẹn und erste Aussaat; alsdaun Abreiben der Hände mit 1.13 prozentiger Schwefelammoniumlösung und zweite Aussaat.

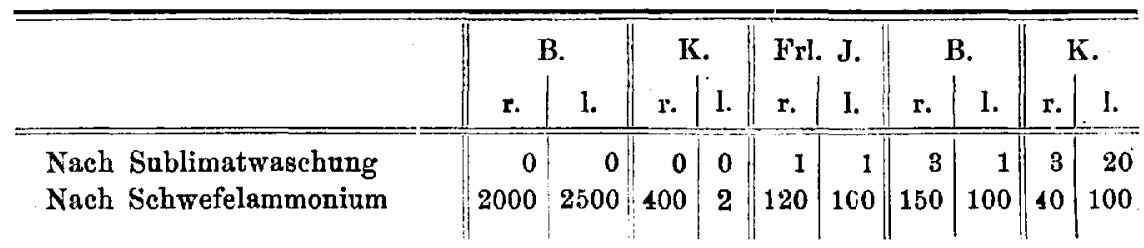

Wir müssen daher als sicher annehmen, daß bei allen Sublimatversuchen die guten Resultate zum großen Teil nicht dureh Abtötung, sondern durch Entwicklungshemmung bedingt, oder, wenn man so sagen wil], vorgetäuscht werden.

Auf die Frage, welche Folgerungen man für die Praxis daraus ziehen soll, kommen wir noch zurück. Speck, Bechhold, Grasberger machen geltend, $d a b$ in der Praxis die Entwicklungshemmung in längerer oder kürzerer Zeit in der Regel zur Abtötung führen wird, so da $B$ wir uns praktisćh mit dem Ergebnis einer so starken nachhaltigen Entwicklungshemmung, wie sie das Sublimat zur Folge hat, im allgemeinen würden begnügen können. $\mathrm{Da} B$ in manchen Fällen, z. B. bei Bakterien, die hinterher im Darm mit. Schwefelwasserstoff in Berübrung kommen, auch unter praktischen Verhältnissen die Wirkung des Sublimats ähnlich wie in vitro neutralisiert werden kann, haben die genannten Autoren schon hervorgehoben. In jedem Fall wird man den Alkohol insofern als ein besonders zuverlässiges Mittel zur Händedesinfektion ansehen müssen, weil bei ihm die nachträgliche Entwicklungshemmung keine Rolle spielt. Man hat bekanntlich früher gerade die Alkoholwirkung als "Scheindesinfektion" bezeichnet; in Wirklichkeit ist der Alkohol, bei dem eine Adsorption des gelösten Des- 
infiziens seitens der Balsterien und eine dadureh bedingte Entwickhngshemmung nicht in Frage kommt, das einzige Mittel, bei dem wir sicher sind, da $B$ das Versch winden der Bakterien ausschlieBlich auf Abtötung beruht.

In einer anderen Hinsicht hat dagegen Sublimat nicht nur vor dem Alkohol, sondern auch vor allen anderen Mitteln einen großen Vorzug, nämlich bezüglich seiner starken prophylaktischen Wirkung, auf die wir weiter unten ausführlicher eingehen.

Sehr viel schlechter als Seifol wirkte der offizinelle Seifenspiritus, der bekanntlich von Mikulicz u. a. zur Händedecinfektion empfohlen worden ist. Bekunntlich hört bei weitergehender Verdünnung die Des infektionskraft des Alkohols bald vollständig auf, und wir können nach unseren Ergebnissen von der Benutzung eines Alkohols unter etwa 70 Prozent nur abraten.

Im Vergleich mit den erwähnten Verfahren ergaben alle übrigen in den vorstehenden Tabellen aufgeführten Mittel erheblich schlechtere Resultate. So wurden stark infizierte Hände durch Bürsten in 5prozentige Lysol-bzw. Kresolseife nur in 45 Prozent keimfrei, durch 3prozentiges Karbol sogar nur in 10 Prozent. Diese beiden Mittel sind aber in unseren amtlichen Anweisungen neben dem $0 \cdot 1$ prozentigen Sublimat empfohlen, obwohl sie in ihrer Wirkung erheblich hinter ihm zurückstehen. Das hat schon Speck in Flügges Laboratorim nachgewiesen, dessen Versuche wir also bestätigen können.

Auch bei Kresol und Karbol, die von den Bakterien ebenfalls aus ihren Lösumgen adsorbiert werden, müssen wir uns fragen, ob dic Ergebnisse zum Teil durch Entwicklungshemmung bedingt sind, ob es sich also anch hier, wenn man so will, oft nur um eine "Scheindesinfektion" handelt. Phenol und Kresol werden aber lange nicht in so hohem Maße wio S.lblimat adsorbiert und unsore unten mitgeteilten Neutralisationsversuche sprechen nicht dafür, daß bei ihnen die Entwicklungshemmung eine wesentliche Rolle spielt.

Fuir die Praxis wichtig ist, daß auch kleine Mengen - etwa 5 cem Seifol und Alkohol -, wenn sie ohne Anwendung von Watte oder Gaze einfach auf den Händen verrieben werden, bereits verhältnismäßig gut wirken.

Auch das einfache Verreiben von $5 \mathrm{ccm}$ Sublimatlösung haben wir auf Flügges Empfehlung hin versucht. Die Ergebnisse sind lange nicht so gut, wie beim Waschen in einer Schüssel mit Sublimatlösung; bei der Einfachheit und Billigkeit des Verfahrens ist dasselbe aber für manche Zwecke der Praxis sicherlich sehr geeignet; allerdings ergeben andere Mittel, wie Quecksilberoxycyanid und Sagrotan, gerade bei dieser Art der Anwendung viel bessere Resultate (vgl. unten). 
Ähnlichen Erfolg hatte bei unseren Versuchen das Waschen mit Afridolseife; bei dem hohen Preise der Seife dürfte ihre Anwendung für die Praxis wohl nicht besonders zu empfehlen sein, wenngleich die Verwendung eines Quecksilberpräparates in fester Form vielleicht für manche Zweckc pralitisch sein mag.

Lysoform in 3prozentiger Lösung hat entsprechend seiner geringen Desinfektionskraft in vitro eine selhr mangelhafte Wirkung.

Bei den in Tabelle 3 und 4 wiedergegebenen Versuchen mit schwäeher infizierten Händen sind die Ergebnisse naturgemäß entsprechend günstiger, während die Reihenfolge der einzelnen Mittel annähernd dieselbe bleibt.

Durch einfaches Waschen mit Seife in flieBendem Wasser kounten wir starkinfizierte Hände niemals, sehwachinfizierte in 13 bzw. 23 Prozent soweit keimfrei machen, daß unsere Platten steril blieben. Beim Waschen in der Waschschüssel erhielten wir auch bei schwacher. Infektion niemals Keimfreiheit, in der Regel sogar noch über 100 Keime; offenbar werden dabei die Hände durch das Waschwasser immer aufs nene verunreinigt, wie schon Gäthgens hervorgehoben hat.

Die mitgeteilten Versuchsreiken schienen uns noch weiterer Bestätigung und Ergänzıng zu bedürfen. Wir haben daher zunächst die wichtigsten der bisher erprobten Mittel: 0.1 prozentiges Sublimat, 80 prozentigen Alkohol und als Vertreter der Kresolmittel Betalysol, nach den Versuchen von Neufeld, Sehiemann und Karlbaum das beste Lysoleraatzmittel, in $2^{1} / 2$ prozentiger Lösung, in erbeblich größeren Versuchsreihen weiter geprüft, und zwar in der überwiegenden Mehrzahl der Versuche unter regelmäßigem Wechsel der Vèrsuchspersonen, wie oben S. 4 beschrieben wurde. Wir haben bei den folgenden Versuchen meistens ein Gemisch von drei verschiedenen Colistämmen benutzt, die wir öfter frisch züchteten; dann ist man gegen plötzliche Ab̧schwächung der Kultur einigermaßen gesichert. Sodann haben wir, nachdem wir die unten (vgl: Absebnitt VI) beschriebene unerwartet lange Nachwirkung des Sublimats kennen gelernt hatten, Hände, die mit einem Quecksilbermittel in Berührung gekommen waren, entweder, wie übrigens auch schon in der Mehrzahl der in den Tabb. 2 bis 4 enthaltenen Versuche, am n̈ächsten Tage nicht wieder zu cinem Desinfektionsversuch gebraucht oder aber bald nach der Desinfektion in 1.13 prozentiger Schwefelammoniumlösung gründlich gewaschen.

$\mathrm{Zu}$ unseren weiteren Versuchen haben wir dann noch einige andere Mittel herangezogen, so neben dem Sublimat Sublamin und Quecksilberoxycyanid. Sie haben den Vorzug, auch von empfindlichen Händen gut vertragen zu werden; auch wir haben uns davon überzeugt, daß Personen, die nach Sublimat Ekzeme bekamen, beide Mittel ohne weiteres ver- 
trugen. Sie lassen sich daher auch in starken Konzentrationen anwenden, und wir haben versucht, ob man dann eine noch sicherere Wirkung erreicht, als mit Sublimat, das kaum stärker als 0.1 prozentig zu verwenden ist. Ferner versuchten wir durch Kombination von Sublimat und Alkohol die Ergebnisse zu verbessern.

Nun gibt es neuerdings auch in der Kresolreihe ein Mittel, das ohne Schaden in sehr hoher Konzentration benutzt werden kann, nämlich Sagrotan (Schottelius, Unna). Auch dieses haben wir, nachdem die ersten Versuche, bei denen nur $5 \mathrm{ccm}$ des Mittels gebraucht wurden, überraschend gut ausgefallen waren, genauer untersucht. Ferner haben wir Jodtrichlorid und $\mathrm{H}_{2} \mathrm{O}_{2}$ herangezogen, die mehrfach zur Händedesinfektion empiohilen worden sind.

Wir haben in den folgenden Versuchen die Hände meistens, anstatt sie in einer Schüssel mit Desinfektionslösung zu waschen, mit $20 \mathrm{ccm}$ der betreffenden Desinfektionslösung mittels eines Wattebausches abgerieben; dieses Verfahren ist, was besonders bei den teuern Mitteln ins Gewicht fällt, natürlich viel sparsamer.

Die Infektion entsprach in allen folgenden Versuchen dieses Abschnittes der ,starken Infektion" in Tabelle 2; die Hände wurden vorher stets zur Beseitigung der Hautsaprophyten mit Alkohol abgerieben und dann mit 2 bis 4 Tropfen einer Coliabschwemmung (1 Kultur in $10 \mathrm{ccm} \mathrm{1:6} \mathrm{ver-}$ dünnter Bouillon) infiziert.

Tabelle 6.

Die Hände werden mit einer dichten Aufschwemmung von Bact. coli infiziert, darauf mit je $5 \mathrm{ccm}$ des Mittels ohne Watte einfach abgerieben.

\begin{tabular}{|c|c|c|c|c|c|c|c|}
\hline $\mathrm{Je} 16$ & Vers & uche & 0 & $1-10$ & $10-100$ & $100-1000$ & über 1000 \\
\hline $\begin{array}{l}\text { Sublimat } \\
\text { Alkohol }\end{array}$ & $\begin{array}{r}0.1 \\
80\end{array}$ & Proz. & $\begin{array}{l}7=43 \cdot 8 \% \\
7=43 \cdot 8\end{array}$ & $\begin{array}{l}5=31 \cdot 3 \% \\
4=25\end{array}$ & $3=\overline{18} \cdot 7 \%$ & $\begin{array}{l}1=6 \cdot 2 \% \\
2=12 \cdot 5\end{array}$ & $\begin{array}{c}3=18 \cdot 7 \% \\
-\end{array}$ \\
\hline Sagrotan & 100 & $n$ & $16=100$ & - & - & - & - \\
\hline Sagrotan & 50 & " & $15=93 \cdot 8$ & $1=6 \cdot 2$ & - & - & - \\
\hline Sagrotan & 10 & $"$ & $9=56 \cdot 3$ & $3=18 \cdot 7$ & $4=25$ & - & - \\
\hline
\end{tabular}

Tabelle 7.

Starke Infektion mit Bact. eoli (Gemisch). Danach Abreiben mit $5 \mathrm{cem}$ des Desinfektionsmittels ohne Watte. Tägliche Neutralisation mit $\left(\mathrm{NH}_{4}\right)_{2} \mathrm{~S}$. Je 16 Versuche. 8 Versuchspersonen, die regelmäBig wechseln. Hg-Oxycyanid aus Tabletten der Firma v. Pieverling hergestellt.

\begin{tabular}{|c|c|c|c|c|c|}
\hline & 0 Keime & $1-10$ & $10-100$ & $100-1000$ & $>1000$ \\
\hline $\begin{array}{l}0.1 \text { Proz. Sublinat } \\
1 \text { Proz. Sublamin } \\
1 \text { Proz. Hg-Oxycyanid } \\
100 \text { Proz. Sagrotan }\end{array}$ & $\begin{aligned} 3 & =18 \cdot 7 \% \\
15 & =93 \cdot 8 \\
11 & =68 \cdot 7\end{aligned}$ & $\begin{array}{l}8=\overline{0} \cdot 0 \% \\
1=6 \cdot 2 \\
4=25 \cdot 0\end{array}$ & $\begin{array}{l}2=12 \cdot 5 \% \\
3=18 \cdot 7 \\
1=\overline{6} \cdot 3\end{array}$ & $\begin{array}{c}6=37 \cdot 5 \% \\
2=12 \cdot 5 \\
-\end{array}$ & $\begin{array}{c}8=50 \cdot 0 \% \\
- \\
-\end{array}$ \\
\hline
\end{tabular}


Tabelle 8.

Starke Infektion der Hände mit Bact. coli (Kultur II). Danach 2 Min. Waschen in 0.1 prozentiger Sublimatlösung bzw. Abreiben mit $20 \mathrm{ccm} 80$ prozentigem Alkohol, $2^{1 / 2}$ prozentigem $\beta$-Lysol oder 50 prozentigem Sagrotan mittels Gazebausch.

Je 16 Versuche.

\begin{tabular}{|c|c|c|c|c|c|c|c|}
\hline & & & $\begin{array}{c}0 \\
\text { Kol. }\end{array}$ & $\begin{array}{l}1-10 \\
\text { Kol. }\end{array}$ & $\begin{array}{c}10-100 \\
\text { Kol. }\end{array}$ & $\begin{array}{c}100-1000 \\
\text { Kol. }\end{array}$ & $\begin{array}{l}\text { über } 1000 \\
\text { Kol. }\end{array}$ \\
\hline $0 \cdot 1$ & Proz. & Sublimat & $14=87.5 \%$ & $2=12 \cdot 5 \%$ & - & - & - \\
\hline 80 & $"$ & Alkohol & $7=43 \cdot 7$ & $2=12 \cdot 5$ & $7=43 \cdot 7 \%$ & 一 & - \\
\hline $21 / 2$ & $"$ & $\beta$-Lysol & - & - & $4=25 \cdot 0$ & $6=37 \cdot 5 \%$ & $6=37 \cdot 5 \%$ \\
\hline 50 & $"$ & Sagrotan & $3=18 \cdot 8$ & $3=18 \cdot 8$ & $9=56 \cdot 1$ & $1=6 \cdot 2$ & - \\
\hline
\end{tabular}

An dem Versuch waren 8 Personen beteiligt, die während 4 Tagen regelmäßig mit dem Desinfiziens wechselten.

Tabelle 9.

Stäke Infektion der Hände mit Bact. coli (Kultur II), danach werden die Hände mit je $20 \mathrm{cem}$ des Desinfiziens mittels Wattebausch abgerieben. Soweit Quecksilberpräparate gebraucht wurden, wurden die Hände jedesmal nach dem Versuche mit 1.13 prozentigem Schwefelammonium gewaschen, um eine störende Nachwirkung: des Sublimats für die Versuche am nächsten Tage auszuschalten. Je 20 Versuche.

\begin{tabular}{|c|c|c|c|c|c|}
\hline & $\begin{array}{c}0 \\
\text { Keime }\end{array}$ & $\begin{array}{l}1 \rightarrow 10 \\
\text { Keime }\end{array}$ & $\begin{array}{c}10-100 \\
\text { Keime }\end{array}$ & $\left|\begin{array}{c}100--1000 \\
\text { Keime }\end{array}\right|$ & $\begin{array}{c}\text { über } 1000 \\
\text { Keime }\end{array}$ \\
\hline Sublamin 1 Prozent & $20=100 \%$ & - & - & - & - \\
\hline Sublamin 0.3 & $18=90$ & $1=5 \%$ & $1=5^{0} \%$ & - & - \\
\hline Sublimat $0.1 "$ & $18=90$ & $1=5$ & $1=5$ & - & - \\
\hline Sublimat-Alkohol & $20=100$ & - & - & - & - \\
\hline 80 Prozent Alkohol & $7=35$ & $6=30$ & $5=25$ & $2=10 \%$ & - \\
\hline $21 / 2 \quad, \quad \beta$-Lysol & $12=60$ & $3=15$ & $2=10$ & $3=15$ & - \\
\hline Jodtrichlorid & $13=65$ & $2=10$ & $1=5$ & $4=20$ & - \\
\hline $\mathrm{H}_{2} \mathrm{O}_{2}$ & $3=15$ & $4=20$ & $1=5$ & $2=10$ & $10=50 \%$ \\
\hline$"$ Iysoform & $2=10$ & $3=15$ & $5=25$ & $3=15$ & $7=35$ \\
\hline Sagrotan & $13=65$ & $4=20$ & $3=15$ & - & - \\
\hline
\end{tabular}

An dem Versuch waren 20 Personen beteiligt, die 10 Tage lang regelmäßig mit den Desinfizientien gewechselt haben.

Wir geben zunächst in den Tabb. 6 bis 18 unsere Versuche wieder, wobei wir die Ergebnisse in fünf Abstufungen einreihen, je nachdem die betreffenden Piatten keimfrei blicben oder bis zu 10, 100, 1000 oder mohr Kolonien erhielten. In einer besonderen Zusammenstellung (Tab. 19) haben wir sodann aus den angegebenen Tabellen diejenigen Versuche übersichtlich nebeneinander gestellt, in denen die wichtigsten Mittel in Mengen von $20 \mathrm{ecm}$ benutzt wurden (nur bei Sublimat wurde zum Teil auch eine 
Waschung in einer Schüssel vorgenommen). In einer zweiten Zusammenstellung (Tab. 20) geben wir eine entsprechende Ubersicht über die Versuche, in denen die Desinfektion mit nur $5 \mathrm{ccm}$ obne Benutzung von Watte oder Gaze geschah.

Tabelle 10.

Die Hände werden mit einer dichten Aufschwemmung von Bact. coli (Gemisch aus 2 frischen und 1 alten Stamm) infiziert, darauf mit je 20 ecin des Mittels mit Wattebausch abgerieben.

Bei den Versuchen wechseln 6 Personen regelmäBig miteinander ab; um die Nachwirkung des Sublimat- und Sublaningebrauches für deu Versuch am folgenden Tage zu vermeiden, wurden die Hände jedesmal nach Beendigung eines Versuches mit einem $\mathrm{Hg}$-Präparat mit 1.13 proz. $\left(\mathrm{NH}_{4}\right)_{2} \mathrm{~S}$ zur Neutralisation abgerieben. Je 20 Versuche.

\begin{tabular}{|c|c|c|c|c|c|}
\hline & $\stackrel{0}{\text { Keime }}$ & $\begin{array}{l}1-10 \\
\text { Keime }\end{array}$ & $\begin{array}{c}10-100 \\
\text { Keime }\end{array}$ & $\begin{array}{c}100-1000 \\
\text { Keime }\end{array}$ & $\begin{array}{l}\text { über } 1000 \\
\text { Keime }\end{array}$ \\
\hline 0.1 Prozent Sublimat & $14=70^{\circ} \%$ & $5=25 \%$ & $1=5 \%$ & - & - \\
\hline $1 \quad, \quad$ Sublamin & $19=95$ & $1=5$ & - & - & - \\
\hline $\begin{array}{l}\text { Sublimat-Alkohol (0.1 Proz. } \\
\text { Sublimat, } 80 \text { Proz. Alkohol) }\end{array}$ & $15=75$ & $3=15$ & $2=10$ & - & - \\
\hline 80 Prozent Alkohol & $5=25$ & $5=25$ & $7=35$ & $3=15 \%$ & - \\
\hline $\begin{array}{lll}21 / 2 & \Rightarrow & \beta-\text { - } y \text { sol } \\
50 & \# & \text { Sagrotan }\end{array}$ & $\begin{array}{l}3=15 \\
5=25\end{array}$ & $\begin{array}{l}1=5 \\
5=25\end{array}$ & $\begin{array}{l}4=20 \\
4=20\end{array}$ & $\begin{array}{l}6=30 \\
4=20\end{array}$ & $\begin{array}{l}6=30 \% \\
2=10\end{array}$ \\
\hline
\end{tabular}

Tabelle 11 .

Starke Infektion der Hände mit Bact. coli (Gemiseh). Danach Abreiben der Hände mit $20 \mathrm{ccm}$ des betreffenden Infektionsmittels mittels Wattebansch. Tägliche Neutralisation mit $\left(\mathrm{NH}_{4}\right)_{2} \mathrm{~S}$ (wegen dauernden Sublimatgebrauches außerhalb der Versuche). Je 42 Versuche. 21 Versuchspersonen, die regelmäBig wechseln.

\begin{tabular}{|c|c|c|c|c|c|}
\hline & 0 Keime & $1-10$ & $10-100$ & $100-1000$ & $>1000$ \\
\hline $50 \%$ Sagrotan & $30=71 \cdot 4 \%$ & $6=14 \cdot 3 \%$ & $6=14 \cdot 3 \%$ & - & - \\
\hline $20 \% \quad "$ & $22=52 \cdot 3$ & $12=28 \cdot 6$ & $5=11.9$ & $1=2.4 \%$ & $2=4.8 \%$ \\
\hline $5 \%$ & $7=16 \cdot 7$ & $8=19 \cdot 0$ & $19=45 \cdot 2$ & $3=7 \cdot 1$ & $5=11 \cdot 9$ \\
\hline $21 / 2 \% \quad "$ & $5=11 \cdot 9$ & $10=23 \cdot 8$ & $14=33 \cdot 3$ & $7=16 \cdot 7$ & $6=14 \cdot 3$ \\
\hline $2 \% \%$ Betalysol & $16=38 \cdot 1$ & $6=14 \cdot 3$ & $13=30 \cdot 9$ & $5=11 \cdot 9$ & $2=4 \cdot 8$ \\
\hline $80 \%$ Alkohol & $15=35 \cdot 7$ & $14=33 \cdot 3$ & $12=28 \cdot 6$ & $1=2 \cdot 4$ & - \\
\hline $3 \%$ Lysoform & $\quad-$ & $4=9 \cdot 5$ & $15=35 \cdot 7$ & $11=26 \cdot 2$ & $12=28 \cdot 6$ \\
\hline
\end{tabular}

Die Versuche bestätigen zunächst, daß wir kein Verfahren besitzen, um die anscheinend so leichte Aufgabe zu lösen,-die Fingerspitzen von kurz zuvor aufgebrachten Colibazillen mit Sicherheit zu befreien. Weiterhin ergibt aber ein Blick anf die Zahlenreihen der Tabb. 19 und 20, daB die Versuche trotz aller Vorsichts- 
maßnahmen und trotz aller Verbesserungen der Versuchstechnik doch nicht durchweg regelmäßig ausfallen, daß wir also von einer idealen Versuchstechnik, die ùns gestatten würde, auf Grund einzelner Versuche über den Wert eines Mittels als Händedesinfektion zu urteilen, noch weit. entfernt sind.

\section{Tabelle 12.}

Starke Infektion mit Coligemisch, danach Abreiben der Hände mit je $20 \mathrm{ccm}$ $80 \%$ Alkohol mittels Wattebausch. Die Versuche wurden abwechselnd mit und ohne Alkobolwaschung der Hände vor der Infektion ausgeführt. Je 16 Versuche. Regelmäßiger Wechsel der acht Versuehspersonen.

\begin{tabular}{r||c|c|c|c|c}
\hline Damn ergaben & 0 Keime & -10 & -100 & -1000 & $>1000$ \\
\hline $\begin{array}{r}\text { Ohne vorangehende } \\
\text { Alkoholwaschung }\end{array}$ & $S=50.0 \%$ & $6=37.5 \%$ & $2=12.5 \%$ & - & - \\
Mit vorangehender & $7=43.8$ & $6=37.5$ & $3=18.7$ & - & - \\
Alkoholwaschung & $7=43.8$ & - & - \\
Zusammen & $15=46.8$ & $12=37.5$ & $5=15.6$ & - & -
\end{tabular}

Tabelle 13.

Starke Infektion der Hände mit Coligemisch. Danach Abreiben mit $20 \mathrm{ccm}$ $96 \%$ bzw. $80 \%$ Alkohol mittels Wattebausch. Je 60 Versuche. 6 Versuchspersonen, die regelmäBig mit beiden Konzentrationen abwechseln.

\begin{tabular}{c|c|c|c|c}
\hline \hline Dann ergab & 0 Keime & $1-10$ & $10-100$ & $100-1000$ \\
\hline $\begin{array}{c}96 \% \text { Alkohol } \\
80 \%,\end{array}$ & $\begin{array}{l}27=45 \% \\
21=35\end{array}$ & $\begin{array}{l}12=20 \cdot 0 \% \\
19=31.6\end{array}$ & $\begin{array}{l}17=28 \cdot 3 \% \\
10=16.7\end{array}$ & $\begin{array}{c}4=6.7 \% \\
10=16.7\end{array}$
\end{tabular}

Individuelle Unterschiede aus dem obigen Versuch.

\begin{tabular}{|c|c|c|c|c|}
\hline Versuchsperson 2 & $2=10 \%$ & $6=30 \%$ & $9=45 \%$ & $3=15 \%$ \\
\hline u & $16=80$ & $3=15$ & $1=5$ & - \\
\hline
\end{tabular}

Wir haben schon betont, daß unter diesen Umständen ein genauer Vergleich immer nur innerhalb derselben Versuchsreihe zulässig ist; in der Tat gleichen sich dann die Unregelmäßigkeiten zum. großen Teil aus. Trotzdem ist es natürlich von Interesse, die mit den einzelnen Mitteln erhaltenen Ergebnisse aus allen Reihen zusammenzuzählen und daraus wiederum die Prozentzahlen zu berechnen; wir geben daher auch diese Berechnung in unserer Ubersicht wieder, möchten aber ausdrücklich hervorheben, da.B man diese Durchschnittszahlen nur unter Vorbehalt benutzen darf.

Als Ursachen des ungleichmäßigen Ausfalles der einzelnen Reihen kommen zunächst die schon hervorgehobene schwankende Resistenz der Colistämme sowie die individuellen Unterschiede de: Versuchspersonen in 
Betracht - Einflüsse, die wir durch die oben angegebenen Verbesserungen der Versuchsanordnung innerhalb der Versuchsreihen auszuschalten uns bemüht haben.

\section{Tabelle 14.}

Starke Infektion der Hände mit Bact. coli (Stamm 4071). Danach Abreiben mit 20 ccm des Desinfektionsmittels mittels Gaze oder Wattebausch, bzw. mit j ccm ohne Gaze und Watte. Je 16 Versuche.

Um die Nachwirkung der Quecksilbermittel auszusehalten, wurden die Hände erst $3 \times 24$ Stunden danach wieder zum nüchsten Versuch benutzt.

\begin{tabular}{|c|c|c|c|c|c|c|}
\hline & Dann ergab & 0 Keims & $1-10$ & $10-100$ & $100-1000$ & $>1000$ \\
\hline $20 \mathrm{ccm}$ & $0.1 \%$ Sublimat & $8=50.0 \%$ & $\begin{array}{l}1=6.2 \% \\
5=31.3\end{array}$ & $\begin{array}{l}5=31.3 \% \\
4=25.0\end{array}$ & $2=12 \cdot 5 \%$ & - \\
\hline $20 \mathrm{~cm}$ & $1 \% \mathrm{Hg}$-Oxycyanid & $16=100$ & - & - & - & - \\
\hline$\tilde{5}$ & $" \quad "$ & $15=93 \cdot 8$ & $1=6 \cdot 2$ & - & - & - \\
\hline $20 \mathrm{ccm}$ & $80 \%$ Alkohol & $13=81 \cdot 3$ & $3=18 \cdot 7$ & - & - & - \\
\hline $5 \eta$ & $" \quad \quad "$ & $8=50 \cdot 0$ & $2=12 \cdot 5$ & $3=18 \cdot 7$ & $3=18: 1$ & - \\
\hline 20 cem & $100 \%$ Sagrotan & $11=68 \cdot 7$ & $5=31 \cdot 3$ & - & - & - \\
\hline$\check{5} \quad$, & $" \quad \quad "$ & $10=62 \cdot 5$ & $5=31 \cdot 3$ & $1=6 \cdot 2$ & - & - \\
\hline
\end{tabular}

Tabelle 15.

Starke Infektion der Hände mit Bact. coli. Darauf Desinfektion und Nentralisation durch Waschen in $1.13 \%$ Schwefelammonium.

$\begin{array}{clrrrrrr}\text { Nach Hg-Oxycyanidwaschung } & 0 & 0 & 1 & 0 & 0 & 0 \\ " \quad \text { Sehwefelammonium } & 1200 & 1000 & 300 & 500 & 40 & 200 \\ \text { " Sublaminwaschung } & 0 & 2 & 15 & 1 & 1 & 3 \\ " \text { Schwefelammonium } & 200 & 200 & 300 & 50 & 50 & 30\end{array}$

Tabelle 16.

Starke Infektion mit Bact. coli. Nach der Desinfektion Neutralisation durch

2 Minuten langes Bewegen der Fingerspitzen in körperwarmem Serum.

$\begin{array}{clrrrr}\text { Nach Sublimatwaschung } & 40 & 40 & - & - \\ ", & \text { Serumneutralisation } & 2000 & 2000 & - & - \\ " & \text { Sublaminwaschung } & 0 & 0 & - & - \\ " & \text { Serumneatralisation } & 1000 & 700 & - & - \\ " & \text { Hg-Oxycyanidwaschung } & 0 & 0 & 0 & 0 \\ " & \text { Serumneutralisation } & 8000 & 8000 & 30 & 40\end{array}$

Nun benutzen wir die Colibazillen nur als Ersatz für die ihnen nahestehenden. pathogenen Arten. Wir haben uns durch Versuche in vitro darüber orientiert, wie letztere durch die wichtigsten Häldedesinfektionsmittel beeinflußt werden. Unsere in Tabb. 18a und b wiedergegebenen Versuche, bei denen wir Sublimat und Alkohol auf verschiedene von uns benutzte Colistämme. bzw. Gemische von solchen 


\section{Tabelle 17.}

Seutralisationsversuche mit $\left(\mathrm{NH}_{4}\right)_{2} \mathrm{~S}$ und körperwarmem Serum nach der Desinfektion mit Bact. coli stark infizierter Hände.

$+=$ deutliche Wirkung der Neutralisation d.h. erheblich vermehrtes Coliwachstum, $?=$ zweifelhafte, $-=$ keine Wirkung der Neutralisation.

$\begin{array}{lrrr}\text { Neutralisation mit }\left(\mathrm{NH}_{4}\right)_{2} \mathrm{~S} & + & ? & - \\ \text { Nach Sublimatdesinfektion } & 12 & 3 & 3 \\ \text { " Sublamindesinfektion } & 7 & - & 1 \\ \text { " Hg-Oxycyanioldesinfektion } & 8 & 1 & 1 \\ \text { Neutralisation mit Serum } & + & ? & - \\ \text { Nach Sublimatdesinfektion } & 2 & 3 & 1 \\ \text { " Sublamindesinfektion } & 2 & - & 8 \\ \text { " Hg-Oxycyaniddesinfektion } & 4 & 2 & 14 \\ \text { " 100\% Sayrotandesinfektion } & - & 2 & 16 \\ \text { " 2\%\% IBetalysoldesinfektion } & - & - & 4 \\ \text { " } 80 \% \text { Alkohol } & - & - & 6\end{array}$

Tabelle 18.

Desinfektionsversuche in vitro.

1 Agarröhrchen in $6 \mathrm{ccrn}$ sterilem Leitungswasser aufgeschwemmt. Davon Einsıtat je 1 Tropfen, auf $1 \mathrm{cem}$ Desinfiziens, Aussaat je 1 Tropfen auf Schrügagar. Lösungen und Verdünnungen mit sterilem Leitungswasser hergestellt, Sublimat aus Pastillen. $+t=$ starkes, $+=$ mïBig starkes Wachstum, $\pm=$ schwaches oder verzögertes Wachstum, - = kein Wachstum.

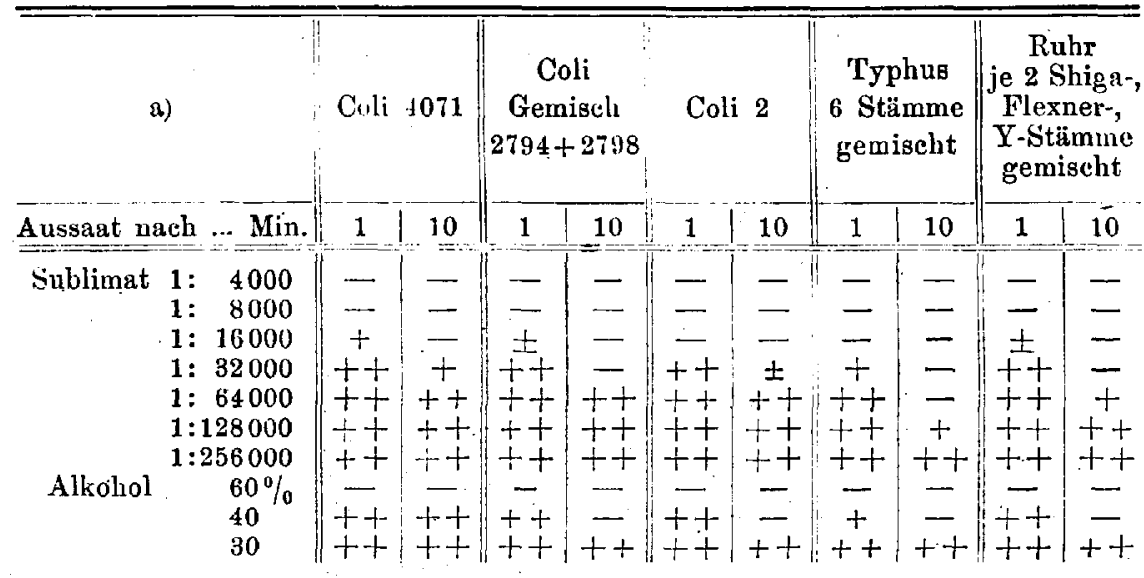

\begin{tabular}{|c|c|c|c|c|c|c|c|c|c|c|c|c|}
\hline b) & & Gem & $\begin{array}{l}\text { isch } \\
94 ;\end{array}$ & $\begin{array}{l}\text { von } \\
7998,\end{array}$ & $\begin{array}{l}\text { Coli } \\
2\end{array}$ & & & & Col & li 2 & & \\
\hline Aussaat nach ... Min. & 1 & 3 & 10 & 30 & 60 & 120 & 1 & 3 & 10 & 30 & 60 & 120 \\
\hline $\begin{array}{cc}\text { Alkohol } 60 \% \\
40 \\
30 \\
\text { Betalysol } 1 / 2 \\
3 / 8\end{array}$ & $\begin{array}{l}-1 \\
++ \\
++ \\
++\end{array}$ & $\begin{array}{l}- \\
+ \\
+ \\
+\end{array}$ & $\begin{array}{l} \pm \\
\pm \\
++ \\
++\end{array}$ & $\begin{array}{c}- \\
++ \\
\pm \\
++\end{array}$ & $\frac{-}{+}$ & $\frac{-}{t}$ & $\begin{array}{l}- \\
\pm \\
++ \\
++ \\
++\end{array}$ & $\begin{array}{l}- \\
- \\
++ \\
+ \\
++\end{array}$ & $\begin{array}{c}- \\
\overline{t+} \\
\pm \\
+t\end{array}$ & $\begin{array}{c}- \\
-t \\
-t \\
+t\end{array}$ & $\frac{-}{ \pm}$ & $\begin{array}{l}- \\
- \\
-5\end{array}$ \\
\hline
\end{tabular}


Tabelle 19.

Zusammenfassung der Desinfektionsversuche mit $20 \mathrm{cem}$

\begin{tabular}{|c|c|c|c|c|c|}
\hline & 0 & -10 & -100 & -1000 & $>1000$ \\
\hline 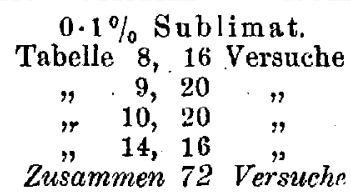 & $\begin{array}{l}14=87 \cdot 5 \% \\
18=90 \cdot 0 \\
11=70 \cdot 0 \\
8=50 \cdot 0 \\
54=75 \cdot 0\end{array}$ & $\begin{array}{l}2=12 \cdot 5 \% \\
1=5 \cdot 0 \\
5=25 \cdot 0 \\
1=6 \cdot 2 \\
9=12 \cdot 5\end{array}$ & $\begin{array}{l}1=5.0 \% \\
1=5 \cdot 0 \\
5=31 \cdot 3 \\
7=9 \cdot 8\end{array}$ & $\begin{array}{l}- \\
- \\
2=12 \cdot 5 \% \\
2=2 \cdot 7\end{array}$ & $\begin{array}{l}- \\
- \\
-\end{array}$ \\
\hline $\begin{array}{c}1 \% \text { Sublamin. } \\
\text { Tabelle 9, } 20 \text { Versucho } \\
" \quad 10,20 \\
\text { Zusammen } 40 \text { Versuche }\end{array}$ & $\begin{array}{l}20=100 \\
19=95 \cdot 0 \\
39=97 \cdot 5\end{array}$ & $\begin{array}{c}- \\
1=5 \cdot 0 \\
I=2 \cdot 5\end{array}$ & $\overline{-}$ & - & - \\
\hline $\begin{array}{l}0 \cdot 3 \% \text { Sublamin. } \\
\text { Tabelle } 9,20 \text { Versucbe }\end{array}$ & $18=90 \cdot 0$ & $1=5 \cdot 0$ & $1=5.0$ & - & - \\
\hline $\begin{array}{l}\text { Sublimat-A k ohol. } \\
\text { Tabelle 9, } 20 \text { Versuche } \\
\text { Zusammen } 40 \text { Versuche }\end{array}$ & $\begin{array}{l}20=100 \\
15=75 \cdot 0 \\
35=87 \cdot 5\end{array}$ & $\begin{array}{l}3=15 \cdot 0 \\
3=7 \cdot 5\end{array}$ & $\begin{array}{l}-\overline{10} \cdot 0 \\
2=5 \cdot 0\end{array}$ & $\bar{z}$ & - \\
\hline $\begin{array}{c}1 \% \text { Hg-Oxycyanid. } \\
\text { Tabelle 14, } 16 \text { Versuche } \\
\text { "17, } 14 \text { " } \\
\text { Zummen } 30 \text { Versuche }\end{array}$ & $\begin{array}{l}16=100 \\
11=78 \cdot 6 \\
27=90 \cdot 0\end{array}$ & $\begin{array}{l}- \\
1=7 \cdot 1 \\
I=3 \cdot 3\end{array}$ & $\begin{array}{l}2=14 \cdot 3 \\
2=6 \cdot 7\end{array}$ & $\overline{-}$ & $\overline{-}$ \\
\hline 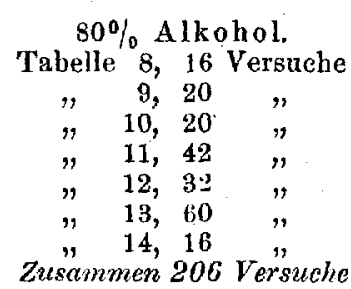 & $\begin{aligned} 7 & =43 \cdot 7 \\
7 & =35 \cdot 0 \\
5 & =25 \cdot 0 \\
15 & =35 \cdot 7 \\
15 & =46 \cdot 8 \\
21 & =35 \cdot 0 \\
13 & =81 \cdot 3 \\
83 & =40.3\end{aligned}$ & $\begin{aligned} 2 & =12 \cdot 5 \\
6 & =30 \cdot 0 \\
5 & =25 \cdot 0 \\
14 & =33 \cdot 3 \\
12 & =37 \cdot 5 \\
13 & =31 \cdot 6 \\
3 & =18 \cdot 7 \\
61 & =29 \cdot 6\end{aligned}$ & $\begin{aligned} 7 & =43 \cdot 7 \\
5 & =25 \cdot 0 \\
7 & =35 \cdot 0 \\
12 & =28 \cdot 6 \\
5 & =15 \cdot 6 \\
10 & =6 \cdot 7 \\
& = \\
46 & =22 \cdot 3\end{aligned}$ & $\begin{aligned} 2 & =10 \cdot 0 \\
3 & =15.0 \\
1 & =2.4 \\
& - \\
10 & =6.7 \\
16 & =7.7\end{aligned}$ & $\begin{array}{l}- \\
- \\
- \\
- \\
-\end{array}$ \\
\hline $\begin{array}{c}100 \% \text { Sagrotan. } \\
\text { Tabelle 14, } 16 \text { Versuche }\end{array}$ & $11=68 \cdot 7$ & $5=31 \cdot 3$ & $40=22 \cdot 0$ & $10=8.8$ & - \\
\hline 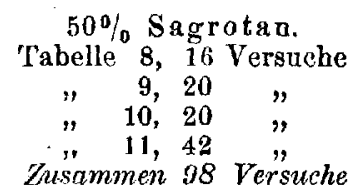 & $\begin{aligned} 3 & =18 \cdot 8 \\
13 & =65 \cdot 0 \\
5 & =25 \cdot 0 \\
30 & =71 \cdot 4 \\
51 & =52 \cdot 0\end{aligned}$ & $\begin{aligned} 3 & =18 \cdot 8 \\
4 & =20 \cdot 0 \\
5 & =25 \cdot 0 \\
6 & =14 \cdot 3 \\
18 & =18 \cdot 3\end{aligned}$ & $\begin{array}{c}9=56 \cdot 1 \\
3=15 \cdot 0 \\
4=20 \cdot 0 \\
6=14 \cdot 3 \\
22=22 \cdot 4\end{array}$ & $\begin{array}{l}1=6 \cdot 2 \\
- \\
4=20 \cdot 0 \\
5=5 \cdot 1\end{array}$ & $\begin{array}{l}=10 \cdot 0 \% \\
2=2 \cdot 1\end{array}$ \\
\hline $\begin{array}{l}20 \% \text { Sagrotan. } \\
\text { Tabelle } 11,42 \text { Versuche } \\
21 / 2 \% \beta-\text { Lysol. } \\
\text { Tabelle } 8,16 \text { Versuche }\end{array}$ & $22=52 \cdot 3$ & $12=28 \cdot 6$ & $5=11 \cdot 9$ & $1=2 \cdot 4$ & $2=4.8$ \\
\hline $\begin{array}{crcc}\text { Tabeile } & 8, & 16 & \text { Versuche } \\
" & 9, & 20 & " \\
" & 10, & 20 & " \\
" & 11, & 42 & \\
\text { Zusammen } & 98 & \text { Versuche }\end{array}$ & $\begin{array}{r}12=60 \cdot 0 \\
3=15 \cdot 0 \\
16=38 \cdot 1 \\
31=31 \cdot 6\end{array}$ & $\begin{array}{r}3=15 \cdot 0 \\
1-5 \cdot 0 \\
6=14 \cdot 3 \\
10=10 \cdot 2\end{array}$ & $\begin{aligned} 4 & =25 \cdot 0 \\
2 & =10 \cdot 0 \\
4 & =20 \cdot 0 \\
13 & =30 \cdot 9 \\
29 & =23 \cdot 4\end{aligned}$ & $\begin{aligned} 6 & =37 \cdot 5 \\
3 & =15 \cdot 0 \\
6 & =30 \cdot 0 \\
5 & =11 \cdot 9 \\
20 & =20 \cdot 4\end{aligned}$ & $\begin{array}{r}6=37 \cdot 5 \\
6=30 \cdot 0 \\
2=4 \cdot 8 \\
14=14 \cdot 3\end{array}$ \\
\hline $\begin{array}{l}3 \% \text { Ly s oform. } \\
\text { Tabelle } 9,20 \text { Versuche } \\
\text { Z" } 11,42 \\
\text { Zusammen } 62 \text { Versuche }\end{array}$ & $\begin{array}{l}2=10 \cdot 0 \\
2=3.2\end{array}$ & $\begin{array}{l}3=15 \cdot 0 \\
4=9 \cdot 5 \\
7=11 \cdot 2\end{array}$ & $\begin{aligned} 5 & =25 \cdot 0 \\
15 & =35 \cdot 7 \\
20 & =32 \cdot 2\end{aligned}$ & $\begin{aligned} 3 & =15 \cdot 0 \\
11 & =26 \cdot 2 \\
14 & =22 \cdot 5\end{aligned}$ & $\begin{aligned} 7 & =35 \cdot 0 \\
12 & =28 \cdot 6 \\
19 & =30 \cdot 6\end{aligned}$ \\
\hline
\end{tabular}


Tabelle 20.

Zusammenfassung der Desinfektionsversuche mit $5 \mathrm{cem}$.

\begin{tabular}{|c|c|c|c|c|c|}
\hline & 0 . & -10 & -100 & -1000 & $>1000$ \\
\hline 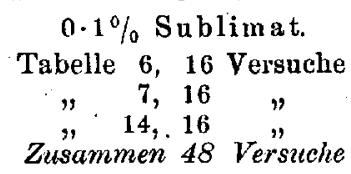 & $\begin{aligned} 7= & 43 \cdot 8 \% \\
& = \\
7= & =14 \cdot 6\end{aligned}$ & $\begin{aligned} 5 & =31 \cdot 3 \% \\
& =\overrightarrow{\mathbf{3 1}} \cdot 3 \\
10 & =20 \cdot 8\end{aligned}$ & $\begin{array}{l}2=\overline{12} \cdot 5 \% \\
4=25 \cdot 0 \\
6=12 \cdot 5\end{array}$ & $\begin{array}{l}1=6 \cdot 2 \% \\
6=87 \cdot 5 \\
2=12 \cdot 5 \\
9=18 \cdot 8\end{array}$ & $\begin{aligned} 3 & =18 \cdot 7 \% \\
8 & =50 \cdot 0 \\
5 & =31 \cdot 6 \\
16 & =33 \cdot 4\end{aligned}$ \\
\hline $\begin{array}{l}1 \% \text { Sublamin. } \\
\text { Tabelle } 7,16 \text { Versuche } \\
1 \% \text { Hg-Oxycyunid. }\end{array}$ & $3=18 \cdot 7$ & $8=50 \cdot 0$ & $3=18 \cdot 7$ & $2=12 \cdot 5$ & - \\
\hline $\begin{array}{c}\text { Tabelle } 7,16 \text { Versuche } \\
\text { " 14, } 16 \text { Vammen } 32 \text { Versuche }\end{array}$ & $\begin{array}{l}15=93 \cdot 8 \\
15=93 \cdot 8 \\
30=93 \cdot 8\end{array}$ & $\begin{array}{l}1=6 \cdot 2 \\
1=6 \cdot 2 \\
2=6 \cdot 2\end{array}$ & $\bar{z}$ & - & - \\
\hline $\begin{array}{l}80 \% \text { Alkohol. } \\
\text { Tabelle 6, } 16 \text { Versuche } \\
\text { Zusammen } 32 \text { Versuche }\end{array}$ & $\begin{aligned} 7 & =43 \cdot 8 \\
8 & =50 \cdot 0 \\
15 & =43 \cdot 8\end{aligned}$ & $\begin{array}{l}4=25 \cdot 0 \\
2=12 \cdot 5 \\
6=18 \cdot 8\end{array}$ & $\begin{array}{l}3=18 \cdot 7 \\
3=18 \cdot 7 \\
6=18 \cdot 8\end{array}$ & $\begin{array}{l}2=12 \cdot 5 \\
3=18 \cdot 7 \\
5=15 \cdot 6\end{array}$ & - \\
\hline $\begin{array}{c}100 \% \text { Sagrotan. } \\
\text { Tabelle } 6,16 \text { Versuche } \\
" 7, \quad 16 c \text { " } \\
\text { Z } 14,16 \text { " } \\
\text { Zusammen } 48 \text { Versuche }\end{array}$ & $\begin{array}{l}16=100 \\
11=68 \cdot 7 \\
10=62 \cdot 5 \\
37-77 \cdot 1\end{array}$ & $\begin{array}{l}-\overline{-} \\
4=25 \cdot 0 \\
5=31 \cdot 3 \\
9=18 \cdot 8\end{array}$ & $\begin{array}{l}1=\overline{6} \cdot 3 \\
1=6 \cdot 2 \\
2=4 \cdot 1\end{array}$ & $\begin{array}{l}- \\
-\end{array}$ & $\begin{array}{l}- \\
- \\
-\end{array}$ \\
\hline $\begin{array}{l}50 \% \text { Sagrotan. } \\
\text { Tabelle 6, } 16 \text { Versuche }\end{array}$ & $15=93 \cdot 8$ & $1=6 \cdot 2$ & - & - & - \\
\hline $\begin{array}{l}10 \% \text { Sagrotan. } \\
\text { Tabelle 6, } 16 \text { Versuche }\end{array}$ & $9=56 \cdot 3$ & $3=18 \cdot 7$ & $4=25 \cdot 0$ & - & - \\
\hline
\end{tabular}

und auf Typhus- und Ruhrbazillen wirken ließnn, ergeben, daß insbesondere manche frischen Colistämme gegen beide Desinfizientien widerstandsfäliger sind wie Typhusbazillen (Gəmisch von 6 frischen Stämmen), während Ruhrbazillen (Mischung von je 2 Stämmen der-3 Typen) sich zum mindesten nicht resistenter zeigten wie Bact. coli. In einigen anderen Versuchen wurden Typhusbazillen bereits durch weit schwächere Sublimatlösungen abgetötet. Hiernach dürfen wir wohl die Colibazillen, und zwar bereits unseren weniger resistenten Stanm Coli II, als geeignetes Testobjekt für solche Versuche ansehen. Der weniger widerstandsfähige Stamm. steht den pathogenen Arten der Typhus-Coligrtuppe wohl am nächsten; andererseits kann man es vielleicht als zweckmäßig ansehen, durch Verwendung resistenter Stämme einen gewissen Sicherheitszuschlag zu erhalten.

Aus anderen Versuchen, die in unserem Laboratorium angestellt wurden, sei hier erwähnt, daß Sublimat sowie Alkohol auf Diph theriebazillen noch beträrchtlich stärker wie auf Colibazillen wirken. Bezüglich der Kresolmittel ergaben die von Neufeld und Karlbaum mitgeteilten Versuche das gleiche für Betalysol; auch auf Typhus wirkte dieses Mittel mindestens so stark wie auf Coli. Das gleiche ergaben spätere Versuche 
für Sagrotan. Diè für die Hädedesinfektion am Krankenbett hauptsächlich in Betracht kommenden Bakterien werden also von den genannten Desinfizientien mindestens ebensogut, meist noch stärker beeinflubt wie Colibazillen, und wir können die Ergebnisse unserer Händedesinfektionsversuche mit Bact. coli als Testobjekt daher wohl als allgemeingültig ansehen. Bezüglich der Unterschiede zwischen den einzelnen Colistämmen zeigte sich besonders in Tab. $18 \mathrm{~b}$ der in den Versuchen der Tabb. 2 bis 4 fast ausschlieBlich benutzte Stamm II gegen Alkohol erheblich weniger resistent wie das Gemisch von 3 Stämmen, das wir in der Mehrzahl der späteren Versuche verwendeten. Deutlich sind die Unterschiede auch in Tab. 18a, wo der Colistamm 4071, der bei den Händedesinfektionsversuchen mit Sublimat (Tab. 14) auffallend schlechte Resultate ergab, sich auch in vitro besonders widerstandsfähig erwies.

Von Interesse ist aber vor allem auch der Vergleich zwischen den Leistungen von Sublimat und Alkohol. In vitro wirkte Sublimat 1:16000, also die 16fache Verdünnung der zur Händedesinfektion benutzten Lösung, meist schon in einer Minute abtötend (in anderen Versuchen war die Wirkung zum Teil noch erheblich stärker), während Alkohol bei der Verdünnung von 40 Prozent bereits an der Grenze der Wirksamkeit stand und bei 30 Prozent nur bei einer Einwirkungszeit von einer Stunde eine schwache Wirkung entfaltete. Relativ, d. h. im Vergleich zu der Wirkung in vitro, wirkt also Alkohol an den Händen unvergleichlich viel besser wie Sublimat; die Ursache dafür können wir wohl nur darin suchen, dab er weit besser in die Hantspalten eindringt.

Wir haben uns die Frage vorgelegt, ob neben den genannten Umständen, die wir für den unregelmäBigen Ausfall der Versuche an den Häden verantwortlich machen müssen, vielleicht auch die Sorgfalt, mit der die Desinfektion ausgeführt wird, eine Rolle spielt. Besonders eifrig erwiesen sich bei den auf die Dauer etwas ermüdenden Versuchen die Teilnehmerinnen unserer Kurse für bakteriologische Hilfsarbeiterinnen (Tabb. 6, 9 und 11), etwas weniger Interesse zeigten vielleicht die Aufwartefrauen unseres Instituts (Versuche in Tabb. 7, 8, 10, 12, 13); es lag nahe, anzunehmen, daß damit der durchschnittlich bessere Ausfall der erstgenannten Versuchsreihen zusammenhängt. Zahlreiche Einzelbeobachtungen sowohl an coliinfizierten Händen wie besonders auch an der Tageshand lassen uns eine solche Vermutung aber als ebenso unwahrscheinlich erscheinen wie die weitere naheliegende Annahme eines grundsätzlichen Unterschiedes zwischen Händen, die durch tägliche grobe Arbeit rauh und rissig sind, und gepflegteren glatten Händen. Wir haben darauf von Anfang an geachtet, aber bei unseren vielfachen Versuchen gefunden, daB ein solcher Unterschied zum mindesten durchgehend nicht besteht. Eher in Betracht kommt zur Erklärung der erwähnten Verschiedenheiten eine andere Möglichkeit, daß nämlich an den Händen der Kursistinnen, die sich täglich mehrmals mit Sublimat wuschen, trotz der Neutralisation durch Schwefel dennoch in der Tiefe der Hautspalten Spuren von Sublimat übrig geblieben sind. 
Die Quecksilbermittel erscheinen nach unseren ausgedehnten Versuchen nicht nur als die wirksamsten Mittel gegenüber den Bakterien der Coligruppe, sondern sie geben auch im allgemeinen die regelmäßigsten Reihen. In 202 Versuchen erhielten wir $173 \mathrm{mal}$ keimfreic Platten, nur 2 mal fanden sich über 100,12 mal 10 bis 100 und 15 mal 1 bis 10 Keime. Nach unseren Versuchen verdient die 0.1prozentige Sublimatlösung, die zudem unsere weitaus billigste Desinfektionslösung ist, durchaus dic hervorragende Stellung, die ihr ins $\rightarrow$ besondere Flügge für die hygienische Händedesinfektion zngesprochen hat.

Bei der starken Wirkung des Mittels auf Colibazillen treten die individuellen Unterschiede der einzelnen Versuchspersonen sehr zurück; da $B$ solche Unterschiede gerade dem Sublimat gegenüber in ausgesprochener Weise bestehen, beweisen die von Landau mitgeteilten Versuche an der Tageshand sowie unsere unten in Abschnitt VI wiedergegebenen Beobachtungen bezüglich der Danerwirkung des Sublimats.

Erheblich schlechter als bei allen anderen Versuchsreihen erscheint die Wirkung des Sublimats in Tab. 14, wo wir zum ersten Male bei 2 unter 16 Versuchen Keimzahlen nahe an 1000 erhiclten, ferner $5 \mathrm{mal}$ Zahlen zwischen 10 und 100. Die Versuche fallen erhebl ch aus dem Rahmen der übrigen heraus und zwar offenbar deshalb, weil der damals benutzte neu gezüchtete Colistamm, wie auch der Versuch in vitro (Tab. 18a) beweist, besonders widerstandsfähig war.

In Vergleich mit Sublimat ergab Sublimat-Alkohol (80prozentiger Alkohol mit 0.1 Prozent Sublimat) eine so geringe Verbesserung (Tab. 9), de. $b$ er mit Riicksicht auf den hohen Preis kaum besonders empfohlen werden kann. Dagegen kommen sowohl Sublamin wie Quecksilberoxycyanid praktisch sehr in Betracht, zunächst für Hände, die Sublimat nicht vertragen; eine 0.3 prozentige Sublaminlösung dürfte dabei etwa der $0 \cdot 1$ prozentigen Sublimatlösung gleichwertig sein. Beide genannten Quccksilbermittel lassen sích aber auch in 1prozentiger Lösung anwenden und wirken dann zweifellos stärker wie die $0 \cdot 1$ prozentige Sublimatlösung. Sublamin ergab in dieser Konzentration unter 40 Versuchen 39 keimfreie Platten und nur 1 mal eine Platte mit 5 Keimen, Quecksilberoxycyanid bei den ersten 16 Versuchen (Tab. 14) stets ktimfreie Platten. Daß dieses Mittel aber ebensowenig wie irgend ein anderes unfehlbar ist, zeigte sich gelegentlich der in Tab. 17 nur summarisch wiedergegebenen Neutralisationsversuche; wir erhielten unter 14 Versuchen (vor der Neutralisation) in 3 Fällen Colikeime auf den Platten, 2 mal sogar über 10 Kolonien. Es ist gewiß Zufall, daß das Quecksilberoxycyanid hiernach in der Zusammenstellung der Tab. 19 etwas schlechter wirksam wie Sublamin in gleicher. 
Konzentration erscheint. An der Tageshand ergeb es bessere Resultate als Sublamin; dabei fanden wir die Hg-Oxycyanidtabletten der Firma v. Pieverling in München erheblich wirksamer als ein Oxycyanid von Merek, während in vitro ein solcher Unterschied nicht erkemmbar war.

Auch die in Tab. 20 zusammengefaßten Versuche, bei denen wir die Finger einfach mit $5 \mathrm{ccm}$ der betreffenden Desinfektionslösung (die aus einer Pipette oder einem kleinen Meßzylinder allmählich über die Fingerspitzen gegossen wurde) kurz wuschen, ergaben eine besonders gute Wirkung bei dem Quecksilberoxycyanid, nämlich 30mal Keimfreileit unter 32 Ver suchen, während Sublimat nur 7 keimfreie, dagegen 25 Platten mit über 100 Keimen unter 48 Versuchen ergab. Hiernach möchten wir das Qilecksilberoxycyanid insbesondere anch für eine derartige Schnelldesinfektion empfehlen.

Sowohl Sublamin wie besonders Quecksilberoxycyanid sind bereits an sich teurer als Sublimat, dazu kommt noch ihre Anwendung in stärkerer Konzentration.

Einen Nachteil haben num aber die genannnten Quecksilbernittel mit dem Sublimat gemeinsam: auch bei ihnen handelt es sich, ebenso wie es vorhin für Sublimat gezeigt wurde, da, wo unsere Platten steril bleiben, zum großen Teil nicht um Abtötung, sondern um Entwicklungshemmung. Die Tab. 15 zeigt, daß auch lier nach Neutralisation durch Schwefelammonium ein großer Teil der Colikeime wieder zum Vorschein kommt.

Wir haben schon oben dartuf hingewiesen, daB nach dem Urteil der meisten Autoren eine derartige Neutralisierung durch schwefelhaltige Stoffe in der Praxis nur in seltenen Fällen $z u$ befürchten ist, so dab man sich praktisch mit diesem Nachteil allenfalls wird abfinden können. Weitere Versuche haben uns aber gezcigt, daß auch eiweißhaltige Lösungen eine ähnliche Wirkung haben können. Bewegten wir die Hände nach dem'Gebrauch der Quecksilbermittel einige Minuten in einer Petrischale mit etwa $40^{\circ}$ warmem Serum, so kamen oft wieder zahlreiche Colikolonien zum Vorschein (Tab. 16).

Diese Tabelle gibt ebenso wie die vorhergehende Beispiele für cine starke Wirkung der Neutralisation; in der folgenden Tabelle 17 geben wir eine Zusammenfassung aller Versuche betreffend die neutralisierende Wirkung von Schwefelammonium und Serum. Danach ist die neutrali sierende Wirkung des Serums durchaus ñcht so regelmäBig wie die des Schwefelammoniums, sie erscheint uns aber praktisch doch etwas bedenklicher. Besonders t.ifft das für die chirurgische Händedesinfektion zu, von der an dieser Stelle aber nicht die Rede sein soll. Aber auch bei den 
Keimen der Typhusgruppe kann in der Praxis viellejcht gelegentlich cine Neutralisierung durch eiweißhaltige Nahrungsmittel, z. B. Milch, vorkommen. Gewiß wird das aber immer eine seltene Ausnahme sein, und wir müssen uns gegenwärtig halten, daß diesem Nachteil der Quecksilbermittel der weit größere Vortcil ihrer einzigartigen prophylaktischen Wirkung gegenübersteht (vgl. unten). Immerhin zeigt sich bei näherem $\mathrm{Zu}$ sehen, daß auch die Quecksilbermittel noch einiges zu wünschen übrig lassen und daß wir auch unter ihnen das ideale Händesdesinfiziens niclıt gefunden haben.

Da auch Seife sich mit Sublimat umsetzen kann, haben wir versucht, ob etwa cine gründliche Seifenwaschung nach der Sublimatdesinfektion wieder Colibazillen zum Vorschein kommen läßt; das war aber in 10 Versuchen niemals deutlich der Fall.

Der 80prozentige Alkohol ergab bei Verreiben von $20 \mathrm{ccm}$ nit Watte oder Gaze recht gleichmäßige Erfolge. Es ist gewiß kein Zufall; daB wir un'er 206 Versuchen niemals über 1000 Keime und nur 16 mal über 100 Keime auf unseren Platten erhielten; die Wirkung des Alkohols kommt aber mit 40 Prozent keimfreier Platten im Durchsehnitt aller Versuche der der Quecksilbermittel, die im Durchschnitt 75 bis 97 Prozent keimfreier Platten und nur 2 mal Platten mit über 100 Kolonien aufwiesen, lange nicht gleich.

Ein Beispiel für die individuellen Verschiedenheiten bei der Wirkung des Alkohols geben wir bei der Tab. 13 wieder.

Als großen Vorzug des Alkohols haben wir schon hervorgehoben, daß bei ilm ein Scheinerfolg durch Entwicklungshemmung nicht in Frage konmt; dementsprechend war auch die Nachbehandlung mit Serum hier erfolglos. Ferner ist der Alkohol ungiftig, geruchlos und verdunstet schnell, so daß Abtrocknen nach der Desinfektion nicht notwendig ist. Ein grober Naehteil ist natülich der hobe Preis.

Wir haben oben schon hervorgehoben, daß der Alkohol in diesen Versuchsreihen lange nicht so gut gewirkt hat wie in den in Tab. 2 wiedergegebenen Versuchen. Nun war in einer Beziehung die Versuchsanordnung anders, indem wir neuerdings die Hände vor der Infektion mit Coli mit Alkohol reinigten, um die oft störenden Hautkeime auszuschalten. Es erschien nicht ganz unmöglich, daß die Colibazillen in die durch Alkoholgebrauch getrocknete und entfettete Haut anders eindringen oder sonst sich bei der nachfolgenden Desinfektion irgendwie anders verhalten könnten; wir haben daher eigens an je 16 Händen einen Versuch mit und ohne vorhergehende Alkoholbehandlung gemacht, ohne jedoch einen Unterschied zu finden (Tab. 12). Ein weiterer Unterschied war, daß wir in den Versuchen der Tab. 2 in der Regel 96 prozentigen, in unseren späteren Yersuchen dagegen stets 80 prozentigen Alkohol benutzten. In der Tat wirkt, wie die Versuchsreihe der Tab. 13 an je 60 Händèn zeigt, bei unserer Versuchsanordnung, $d . h$, auf dünne, nicht völlig trockene 
Bakterienschichten, 96 prozentiger Alkohol stärker als 80 prozentiger. Der Unterschied ist aber nicht sehr erheblich, und für die Praxis, wo man immer mit Bakterien rechnen $\mathrm{muB}$, die in trockene Bakterienschichten eingebettet sind, ist, wie schon bemerkt wurde, der 96 prozentige Alkohol nicht anwendbar (vgl. auch die Tab. 23). Hauptsächlich sind die günstigeren Ergebnisse mit Alkohol in Tab. 2 aber wohl dadurch bedingt, da B der damals benutzte Colistamm wesentlich weniger resistent war als das später benutzte Gemisch von dei verschiedenen Stämmen; auch ein Versuch in vitro (Tab. 18b) zeigte dentlich diesen Unterschied.

Auch bei einfachem Waschen mit $5 \mathrm{ccm}$ ergibt cer Alkolol bereits gute Resultate, wenn er auch erheblich schwächer wirkt als bei Verwendung von $20 \mathrm{ccm}$. Diès zeigt in Bestätigung der Tab. 2 ein Vergleich innerhalb der Tab. 14, während die Nebeneinanderstellung sämtlicher Versuche offenbar auch hier ein unrichtiges Bijd gibt.

$\mathrm{Zu}$ den besten Händedesinfektion!mitteln müssen wir nach unseren Versuchen auch das Sagrotan rechnen. Onverdüntes Sagrotan in der Menge von $20 \mathrm{ccm}$ mit Watte verrieben, ergab in einer allerding: kleinen Versuchsreihe (an 16 Händen) niemals Keimzahlen iibcr 100. Annähernd ebenso : ünstig wirkte aber bereits einfackes Verreiben von 5 ccm (Tabb. 6, 7, 14). Bei derselben Anwendung wirkte auch 50prozentiges Sagrotan bereits recht gut (Tab.6). Auch dieses Mittel ist daher zur Schnelldesinfektion gecignet.

Bei unseren zahlreichen Versuchen, wo wir 50prozentiges Sagrotan in der Monge von $20 \mathrm{ccm}$ mit Watte oder Gazo verrieben, erhielten wir, wie die Zusammenstellung der Tab. 19 zeigt, im ganzen etwas bessere Ergebnisce als mit 80 prozentigem Alkohol; auffallend ist aber die starke UnregelmäBigkeit der einzelnen Versuchsreihen. Unter 98 Versuchen ergaben nur 7 Versuche mehr als 100, davon aber 2 mehr als 1000 Colikolonien. Besonders groß sind die Unterschiede zwischen den Tabb. 8 und 10 auf der einen, 9 und 11 duf der anderen Seite. Gerade bei so unregelmäßigem Ausfall der Versuche ist es nicht angängig, die Ergebnisse aus verschiedenen Tabellen miteinander unmittelbar in Vergleich zu stellen. So erscheint die 20prozentige Sagrotanlösung in Tab. 11 wirksaner als die 50prozentige in Tab. 8 oder 10; vergleicht man dagegen die betreffenden Zahlen innerhalb der Tab. 11, so ist der bessere Erfolg der stärkeren Lösung de utlich.

Bemerkenswert ist, daß nach Tab. 11 eine $2 \frac{1}{2}$ prozentige Sagrotanlösung beträchtlich und sogar eine 5 prozentige Sagrotanlösung noch etwas schlechter als eine $21 / 2$ prozentige Betalysollösung wirkt; in vitro entsprich t aber gegenüber Aufschwemmungen von Coli und. Staphýlokokken die abtötende Kraft einer Sagrotanlösung nąch Versuchen in unserem Labora- 
torium nahezu der einer doppelt so starken Lösung von Betalysol. Es zeigt sich wiederum, daß selbst bei Desinfizientien, die zur gleichen Gruppe gehören, ein unmittelbarer SchluB aus Vitroversuchen auf das Verhalten bei der Händedesinfektion nicht zulässig ist. Hiernach erschcint für die Härdedesinfektion die Anwendung schwächerer als 10- bis 20prozentiger Sagrotanlösungen kaum empfehlenswert.

Bei Sagrotan spielt die Entwicklungshemmung anschicinend keine erhebliche Rolle, wenigstens ergaben unsere Versuche (Tab. 17) keine deutliche Vermehrung der Keime nach Waschen mit Serum. Eine nachteilige Wirkung des Mittels auf die Hände haben wir bei unseren Versuchspersonen nicht gesehen; der Geruch wurde im allgemeinen nicht unangenchm empfunden. Das Mittel ist im Vergleich nicht nur mit Sublimat, sondern anch mit Lysol recht teuer.

Auch Betalysol in $2 \frac{1}{2}$ prozentiger Lösung erscheint nach unseren 98 Versuchen noch als ein verhältnismäßig gutes Mittel. Wenn es im Durchschnitt aller Versuche das verhältnismäßig gute Resultat von 31 Prozent keimfreien Händen ergab, so zeigen allerdings die 14 Prozent, in denen über 1000 Keime übrig blieben, daß es doch nicht annähernd so zuverlässig wirkt wie die vorher genannten Desinfiziention.

Wir haben das Betalysol in den unten in Tab. 27 wiedergegebenen Versuchsreihen nochmals mit ähnlichem Ergebnis geprüft: bei einem wenig resistenten Colistamm erhielten wir 43 Prozent, bei einem Gemisch von d ei frischen Stämmen 28 Prozent keimfreie Härde. Im einzelnen zeigen jedoch die Versuchsreihen mit Betalysol untereinander erheblich größere Verschiedenheiten als die Versuche mit Alkohol und den Quecksilbermitteln.

Dic Entwicklungshemmung scheint nach unșeren Versuchen (Tab. 17) beim Betalysol keine erhebliche Rolle zu spielen; in vitro lïßt sich allerdings, wie Vas für Karbol fand und wie wir nach Versuchen in unserem Laboratorium für Betalysol und Sagrotan bestätigen können, durch eiweißhaltige Medien, speziell auch durch Serum ein Teil der Wirkung der genannten Mittel neutralisieren.

Schädigungen der Hände haben wir bei vielfachem Gebrauch von Betalysol niemals gesehen; der lange anhaftende Geruch ist allen Kresolmitteln gemeinsam und wird von den meisten recht unangenehm empfunden.

Vergleicht man die Tabb. 6 und 7, in denen jedesmal nur 5 ccm Desinfiziens gebraucht wurden, mit den anderen Versuchsreihen, wo die gleichen Mittel in der Menge von $20 \mathrm{ccm}$ mit Watte verrieben zur Anwendung kamen, so fällt auf, da $B$ Sublimat entsprechend den Ergebnissen der Tabb. 2 bis 4 in kleiner Menge erheblich schlechter wirkt, Quecksilberoxycyanid dagegen und Sagrotan sehr gut, letzteres sogar anscheinend noch besser als bei Anwendung der größeren Menge. Diese parndoxe 
Erscheinung ist wohl von vornherein als Zufall anzusenen, zumal es sich um eine kleine Zahl von Versuchen und zwar um solche, die aus verschiedenen Versuchsreihen stammen, handelt. Wir haben aber in Tab. 14 Sublimat, Quecksilberoxycyanid, Alkohol und Sagrotan unter regelmäBigem Wechsel der Versuchspersonen nochmals eigens in bezug auf die Wirkung kleinerer und größerer Mengen verglichen. Es bestätigte sich in der Tat, daß bei Anwendung so kleiner Mengen Sublimat und Alkohol entsprechend unseren früheren Erfahrungen erheblich schlechter, Sagrotan und Quecksilberoxyeyanid dagegen beinahe ebensogut wie bej Anwendung von $20 \mathrm{ccm}$ wirken. Hiernach dürften für eine Schnelldesinfektion mit kleinen Mengen, wie sie in der Praxis häufig anzuwenden sein wird, die beiden letztgenannten Mittel vorzugsweise zu empfehlen sein.

Die besprochenen Mittel haben wir deswegen in großen Versuchsreihen geprüft, weil wir sic auf Grund früherer Versuche als brauchbar zur Händedesinfektion erprobt hatten. Wir legten aber Wert darauf, daneben ein schwach wirkendes Mittel zum Vergleich heranzuziehen; hierzu wählten wir Lysoform in 3prozentiger Lösung als ein viel gebrauchtes, anscheinend besonders wegen seines Geruches beliebtes Mittel, das wir nach unseren Versuchen für durchaus unzulänglich halten müssen. Es ergab unter 62 Versuchen nur 3 Prozent steriler Platten, dagegen 30 Prozent Keimzahlen über 1000 ; es steht somit weit hinter, den besprochenen Mitteln zurück.

Recht ungünstig erscheint nach Tab. 9 (trotz des damals benutzten, wenig resistenten Colistammes) auch' die Wirkung des Wasserstoffsuperoxyd, das in der Hälfte der Fälle, also noch häufiger als Lysoform; einen Keimrest von über 1000 ergab. Es ist offenbar als Händedesinfiziens ganz unzulänglich. Aber auch Jodtrichlorid, das von uns ebenfalls nur in dieser einen Versuchsreihe (in der es etwa ebenso wirkte wie $2 \frac{1}{2}$ prozentiges Betalysol) herangezogen wurde, ist in Rücksicht auf seine unangenehmen Nebenwirlkungen nicht als gutes Desinfiziens für die Hände anzusehen.

Wir haben schlieblich noch einige Versuche mit Chlorlösungen, nämlich mit der von Andrewes und Ort on für die chirurgische Händedesinfektion empfohlene Chlorlösung sowie mit Eau de Javelle und Dakinscher Lösung angestellt, ferner mit Mea Jodina (Reichert) und mit Providoformtinktur. Alle diese Mittel sind allerdings mehr für die chirurgische Desinfektion vorgeschlagen worden; sie haben hierfür in unseren, an anderer Stelle mitzuteilenden Versuchen sich nicht bewährt und ebensowenig war das bei den Versuchen mit Coliinfektion der Fall, wie die nachstehenden beiden Tabellen zeigen, bei denen zim Vergleich andere, uns ạus früteren Ver- 
suchen bekannte Verfahren lerangezogen wurden. Es erübrigt sich daher, auf die unangenehmen Nebenwirkungen der Mittel näher einzugehen.

Tabelle 21.

Starke Infektion der. Hïnde mit Bact. coli (resistenter Stamm), danach Abreiben mit je $20 \mathrm{ccm}$ Alkohol und Sagrotan mittels Wattebauseh, Schüsselwaschung mit Chlorpräparat nach Andrewes-Ortorr und Lysol.

\begin{tabular}{|c|c|c|c|c|c|}
\hline & 0 & $1-10$ & $10-100$ & $|100-1000|$ & über 1000 \\
\hline $\begin{array}{l}\text { Chlorpräiparat nach Audrewes } \\
\text { und Orton }\end{array}$ & 1 & 1 & 6 & 5 & 3 \\
\hline 50 Prozent Sagrotan & 8 & 1 & 6 & 1 & - \\
\hline $5 \quad, \quad$ Lysol & 7 & 1 & 4 & 4 & - \\
\hline $80 \quad "$ Alkohol & 3 & 9 & 2 & 2 & - \\
\hline
\end{tabular}

Tabelle 22.

Starke Infektion der Hände mit Bact. coli, danach Abrciben mit je $20 \mathrm{cem}$ Alkohol bzw. Providoformtinktur mittels Wattebausch, Schüsselwaschung mit Eau de Javelle, Dakinscher Lösung, „Mea Jodinas" $1: 1000$.

\begin{tabular}{l||c|c|c|c|c}
\hline & 0 & $1-10$ & $10-100$ & $100-1000$ & uber 1000 \\
\hline \hline Eau de Javelle 3 prozentig & - & - & - & 2 & 8 \\
Dakin & - & - & 4 & 4 & 2 \\
Providoform & 4 & - & 4 & 1 & 1 \\
Alkohol 95 Prozent & 2 & 4 & 4 & - & - \\
Mea Jodina & - & - & 2 & 1 & 5
\end{tabular}

Offenbar wirken die Mittel zum Teil deswegen an der Hand so schlecht, weil Chlor und Jod sich mit allen organischen Stoffen leicht umsetzen. Bei der Providoformtinktur ist natürlich der Alkohol an sich bereits wirksam; in unseren Versuchen ist jedenfalls eine Uberlegenheit des Mittels gegenüber dem zur Kontrolle benutzten 95prozentigen Alkohol nicht zu erkennen.

Wir haben nun einige der wichtigsten Desinfizientien noch in der Weise naclgeprült, dəß wir die Hände mit diinnflüssigen Fäzes infizierten, die sterilisiert und reichlich mit Coli versetzt worden waren. Die Ergebnisse zeigt die nachfolgende Tabelle.

Die Desinfektion mit $2 \frac{1}{2}$ prozentigem Betalysol ergab zunächst auffallend gute Erfolge (in seclis Versuchen stets Keimfreiheit), so daß wir vermuteten, unser Colistamm habe sich erheblich abgeschwächt. In der Tat wurde der Erfolg schlechter, als wir den Versuch mit frischen Stämmen wiederholten. Im ibbrigen entsprechen die Ergcbnisse etwa denen, die 
Tabelle 23.

Die Fingerspitzen werden mit Fäzes infiziert, die sterilisiert und dann reichlich mit Bact. coli versetzt sind.

\begin{tabular}{|c|c|c|c|}
\hline & Zahl der Versuche & Mittel & Erfolg \\
\hline & 2 & $\begin{array}{l}96 \text { proz Alkohol, } 20 \mathrm{ecm} \text { mit } \\
\text { Wattebausel verrieben }\end{array}$ & $2 x>100$ Keime \\
\hline & 8 & $\begin{array}{l}\text { 80proz. Alkohol, } 20 \text { cen mit } \\
\text { Wattebausch verrieben }\end{array}$ & $\begin{array}{l}7 \times 0 \text { Keime } \\
1 \times 10 \text { Keime }\end{array}$ \\
\hline & 10 & $\begin{array}{l}90 \text { proz. Seifol, } 20 \mathrm{cem} \text { Init } \\
\text { Wattebausch verrieben }\end{array}$ & $\begin{array}{ll}7 \times 0 & \text { Keime } \\
1 \times 1 & \text { Keim } \\
2 \times 2 & \text { Keime }\end{array}$ \\
\hline & 10 & 2 , Min. Waschen in 0.1 proz. & $10 \times 0$ Keime \\
\hline a) & $\begin{array}{l}6 \text { mit einem wenig re- } \\
\text { sistenten Colistamm }\end{array}$ & 2 Min. Waschen in $2^{1 / 1}$ proz. & a) $6 \times 0$ Keine \\
\hline b) & $\begin{array}{l}4 \text { mit einem Gemisch } \\
\text { von } 3 \text { frischen Coli- } \\
\text { stämmen }\end{array}$ & & 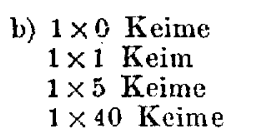 \\
\hline
\end{tabular}

wir mit einfacher Coliaufschwemmung erhielten; wir dürfen daker wobl annehmen, daß im allgemeinen unsere Versuchsanordnung bei Benutzung einfacher Abschwemmung von Colibazillen uns für die Praxis genügend zuverlässige Ergebnisse liefert, und daB in der Tat die Schwierigkeiten der Händedesinfektion nicht in der Umhüllung der Bakterien mit Schmatzschichten, sondern in ihrer versteckten Lage in den Hautspalten begrïndet sind.

In einem Punkte läßt sich jedoch, wie schon oben erwähnt wurde, ein wichtiger Unterschied gegenüber den vorhergehenden Versuchen feststellen. Während nämlich bei Händen, die mit einfachen Abschwemmungen von Bakterien infiziert sind, auch 96prozentiger Alkohol von zuverlässiger Wirkung ist, wirkt an Händen, die mit Fäzes infiziert sind, nur etwa 80 prozentiger Alkohöl sichtr., Dies entspricht den von Huntemüller und Eckard aus unserem Laboratorium mitgeteilten Versuchen mit Prodigiosusbakterien, die in dünnen Schichten Blut oder Serum an den Händen angetrocknet waren. In derartige trockene Schichten dringt absoluter bzw. 96prozentiger Alkohol nicht ein; daher ist in der Praxis überall, wo nicht eine Waschung vorhergeht, die Anwendungabsoluten Alkohols unbedingt zu vermeiden. Wenn der konzentrierte Alkohol auf die Keime der Tageshand ausgezeiethet wirkt, so liegt das daran, daß diese Keime sich eben stets von Natur bereits in einem feuchten Medium befinden. 
Wenngleich für die Desinfektion am Krankenbett überwiegend die Bakterien der Typhus-Coligruppe in Betracht kommen, so haben wir doch auch einige Versuche mit einem Gram-positiven, aus der Luft gezüchteten Coccus gemacht, den wir mit unserem Colibucillus mischten.

\section{Tabelle 24.}

Starke Infektion beider Hände mit einem Gemisch von Bact, coli und einem in Pferdestall aus der Luft gezichteten rosa Coccus. Danach 2 Minuten Waschen in 0.1 proz. Sublimat- bzw. 21/9 proz. $\beta$-Lysollösung. Je 6 Versuche.

\begin{tabular}{|c|c|c|c|c|c|c|c|c|}
\hline & \multicolumn{2}{|c|}{ 0-10 Kol. } & \multicolumn{2}{|c|}{$10-100 \mathrm{Kol}$. } & \multicolumn{2}{|c|}{$100-1000 \mathrm{Kol}}$. & \multicolumn{2}{|c|}{ über $1000 \mathrm{Kol}$. } \\
\hline & Coli & $\begin{array}{l}\text { Iuft- } \\
\text { coccus }\end{array}$ & Coli & $\begin{array}{l}\text { Luft- } \\
\text { coccus }\end{array}$ & Coli & $\begin{array}{l}\text { Luft- } \\
\text { coceus }\end{array}$ & Coli & $\begin{array}{l}\text { Luft- } \\
\text { coccus }\end{array}$ \\
\hline 0:1 Proz. Sublinat & $\mathbf{5}$ & 1 & 1 & 3 & - & 1 & - & 1 \\
\hline $2^{1} / 2 \quad, \quad \beta \cdot$ Lysol & 3 & 1 & 2 & 3 & 1 & 1 & - & 1 \\
\hline
\end{tabular}

Wie zu erwarten war, erwies sich der Coccus als erheblich widerstandsfähiger, und zwar besonders gegen Sublimat, dessen relativ schlechte Wirkung mit Staphylokokken bekannt ist.

Nach unseren mitgeteilten Versuchen erscheint die Wirkung mancher vielgebrauchter Desinfizientien, darunter auch Karbol, recht mangelhaft; aber auch die Kresolseife und ihre Ersatzmittel wirken unsicherer, als man sich wohl gewöhnlich vorstellt. Dennoch glauben wir, da.B diese Mittel da, wo bessere nicht anwendbar sind, mit großem Nutzen verwendet werden. Uberhaupt darf man, wenn man die Versuchsergebnisse richtig deuten will, dic Verhältnisse der Praxis nie aus den Augen verlieren. Nach allen praktischen Erfahrungen ist zweifellos die gewöhnliche Seifenwaschung ein sehr wirksames Mittel zur Verhütung von Kontaktinfelstioneh, obwohl es in unseren Versuchen niemals gelang, stark infizierte Hände dadurch keimfrei zu machen. Für die Praxis genügt es eben in sehr vielen Fällen, wemn der gröbte Teil der infektiösen Keime beseitigt wird; da $B$ das in der Tat beim einfachen Händewaschen der Fall ist, werden wir unten unter Mitteilung weiterer Versuche ausführlicher erörtern.

Wo sich aber in der Piaxis Desinfizientien anwenden lassen, sollte man sie stets an Stelle der einfachen. Waschung gebrauchen, vor allem schon deswegen, weil beim gewöhnlichen Händewaschen dic abgespülten Keime durch Tröpfelien auf Kleider, Fußböden, Möbel usw. verspritzt und Handtücher und Bürsten infiziert werden. Auf diese Gefahr haben Flügge und Speck mit Recht nachdrücklich hingewiesen. Wenn auch clerärt verstreute Keime lange nicht so gefährlich sein werden, wie die an den Händen befindlichen, so ist doch natürlich nach Möglichkeit stets Keimvernichtung und nicht Keimbeseitigung anzustreben. 
Kosten der Desinfektion.

Zum Schlusse sei noch eine Übersicht über die Kosten der wichtigsten Desinfektionsmittel bei Einkauf etwas größerer Mengen nach den früheren Friedenspreisen gegeben; in Klammern sind die Angaben über die Preise im Frühjahr 1918 gesetzt.

$$
\begin{aligned}
& \text { Sublimatpastillen. } \\
& 1 \mathrm{~kg}=12 \cdot 50 \mathrm{M} .(26 \cdot 50 \mathrm{M} \text {.) } \\
& 110 \cdot 1 \text { proz. Lösung }=1 \frac{1}{4} \text { Pfg. (21/2 Pfg.) } \\
& 20 \mathrm{ccm} 0.1 \text { proz. Lösung }=1 / 40 \text { Pfg. (1/20 Pfg.) } \\
& \text { Sublaminpastillen (Preis 1918). } \\
& \text { ] } \lg g=40 \mathrm{M} \text {. } \\
& 20 \mathrm{ccm} \cdot 1 \text { proz. Lösung }=4 / 5 \mathrm{Pfg} \text {. } \\
& \text { Hg-Oxyeyanidpastillen v. Pieverling (Preis 1918). } \\
& 10 \text { Pastillen (je } 0.5 \mathrm{~g}) 55 \mathrm{Pfg} \text {. } \\
& 20 \mathrm{ccm} 1 \text { proz. Lösurg } 2 \cdot 2 \text { Pfg. } \\
& \text { Alkohol (80prozent.). } \\
& 1 \mathrm{~kg}=1250 \mathrm{ccm}=1 \cdot 80 \mathrm{M} .(4 \cdot 48 \mathrm{M} \text {.) } \\
& 20 \mathrm{ccm}=2 \cdot 8 \mathrm{Pfg} .(7 \cdot 1 \mathrm{Pfg} .) \\
& \text { Lysol. } \\
& 1 \mathrm{~kg}=1.75 \mathrm{M} .(5 \cdot 10 \mathrm{M} .) \\
& 115 \text { proz. Lösung }=8 \cdot 7 \mathrm{Pfg} .(25.5 \mathrm{Pfg} .) \\
& 20 \mathrm{ccm} 5 \text { proz. Lösung }=0.17 \text { Pfg. }(0.5 \text { Pfg.) } \\
& \text { Sagiotan. } \\
& 1 \mathrm{~kg}=6 \mathrm{M} \text {. (12 M.) } \\
& 20 \mathrm{ccm} 50 \text { proz. Lösung }=6 \text { Pfg. (12 Pfg.) } \\
& 20 \text {, } 20 \text {, , , }=2 \cdot 4 \text { Pfg. }(4 \cdot 8 \text { Pfg.) }
\end{aligned}
$$

\section{Ist der Gebrauch einer Bürste bei der Händedesinfektion von Vorteil?}

Wir geben nachstehend zunächst eine Versuchsrcihe mit 96 prozentigem Alkohol wieder (s. Tabelle 25).

Das Ergebnis der Versuche ist etwas iberraschend. Die Anwendung der Bürste hat die Resultate nicht verbessert, sondern merklich verschlechtert. Trotz der ziemlich geringen Zohl der Versuche werden wir das Ergebnis der Versuche nicht als zufällig ansehen dürfen, zumal auch Börnstein (dessen Versuche zur Ergänzung in unserer Tabelle beigefügt sind) beim Bürsten in einer Schüssel mit 60 bis 70 prozentigem Alkolol recht, schlechte Erfolge hatte, ebenso wie Huntemüller und Eckardt bei ibren 
Tabelle 25.

Starke Infektion der Hände mit Bact. coli. Die Versuche sind kurz hintereinander, im Verlauf einer Woche, mit demselben Colistamm angestellt, allerdings ohne systematischen Wechsel der Versuchspersonen.

\begin{tabular}{|c|c|c|c|c|}
\hline \multirow[b]{2}{*}{ Verfahren } & \multirow{2}{*}{$\begin{array}{c}\text { Zahl } \\
\text { der } \\
\text { Versuche }\end{array}$} & \multicolumn{3}{|c|}{ Ergebnis } \\
\hline & & 0 & $1-100$ & $\begin{array}{c}\text { über } \\
100 \text { Keime }\end{array}$ \\
\hline $\begin{array}{l}20 \mathrm{ccm} 96 \text { proz. Alkohol oder Seifol } \\
\text { mit Watte verrieben }\end{array}$ & 14 & 11 & 3 & - \\
\hline $\begin{array}{l}5-10 \text { cem } 96 \text { proz. Alkohol (ohne Watte } \\
\text { verrieben) }\end{array}$ & 16 & 11 & 5 & - \\
\hline $\begin{array}{l}2 \text { Min. bürsten in einer Schüssel mit } \\
96 \text { proz. Alkohol }\end{array}$ & 10 & 4 & 4 & 2 \\
\hline $\begin{array}{l}\text { Versuehe von Börnstein, bürsten in } \\
\text { Schüssel mit 60-70proz. Alkohol }\end{array}$ & 24 & 6 & 11 & $\tau$ \\
\hline
\end{tabular}

Versuche aus Tabelle 2 entnommen:

a) 20 ecm 96 proz. Alkohol mit Watte verrieben

b) Die Hände wurden 2 Minuten in 1 Liter 96 proz. Alkohol gebürstet

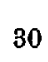

20

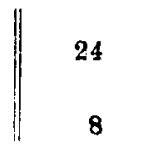

$\mid$\begin{tabular}{l|l}
6 & - \\
8 & 4
\end{tabular}

Versuchen an der Tageshand mit Bürsten in 63prozentigem Phobrolalkohol. In der gleichen Tabelle geben wir noch 30 aus Tabelle 2 entnommene Versuche mit $20 \mathrm{ccm}$ Alkohol und darunter 20 Versuche mit Bürsten in einer Schüssel voll Alkohol wieder, die in dieselbe Versuchsreihe gehören, aber aus Tabelle 2 vorläufig weggelassen wurden. Hier wirkt das Bürsten mit Alkohol viel schlechter als Abreiben mit Watte.

Schließlich haben wir noch eine eigene Versuchsreihe gemacht, wobei die Personen, um individuelle Verschiedenheiten auszuschalten, ganz regelmäbig wechselten; auch hier war das Ergebnis das gleiche.

\section{Tabelle 26.}

Starke Infektion der Hände mit Bact. coli, darauf werden die Hände mit $20 \mathrm{cem}$ 80 proz. Alkohol mittels Wattebausch abgerieben bzw. mit Bürste in der Schüssel mit so proz.Alkohol gewaschen. Die Versuchspersonen wechseln regelmäBig miteinander.

\begin{tabular}{|c|c|c|c|c|c|}
\hline Dann ergaben: & $\begin{array}{l}\text { Zahl der } \\
\text { Versuche }\end{array}$ & $0-10$ & $10-100$ & $100-1000$ & über 1000 \\
\hline Abreiben mit Wattebausch & 24 & 14 & 8 & 2 & - \\
\hline Waschen mit Bürste & 20 & 6 & 8 & 5 & $-^{-1}$ \\
\hline
\end{tabular}


Wir müssen hiernach annehmen, daß der Alkohol beim Verreiben mittels eines Wattebausches viel besser in die feinen Spalten der Haut eindringt, als beim Gebrauch einer Bürste. Ubrigens ist das Bürsten mit Alkohol auch für dic Hände schmerzhaft; $d a ß$ es auch eine große Verschwendung bedeutet, eine Schüssel voll Alkohol zur Desinfektion bereitzustellen, braucht kaum eigens hervorgehoben zu werden.

Auf Grund der Erfahrung bei der Alkoholdesinfektion haben wir dann mehrere Versuchsreihen gemacht, um die Wirkungen von Kresollösungen bei einfacher Waschung, beim Gebrauch einer Bürste und beim Abreiben mittels cines Wattebauschẹs zu vergleichen.

Tabelle 27a.

Starke Infektion mit Colibazillen (Coli II, alte, wenig resistente Laboratoriumskultur). Waschung 2 Min. in $21 / 2$ proz. $\beta$-Lysollösung.

\begin{tabular}{|c|c|c|c|c|}
\hline Es ergab: & $\begin{array}{c}\text { Einfaches } \\
\text { Waschen } \\
\text { (22 Versuche) }\end{array}$ & $\begin{array}{l}\text { Abreiben mit } \\
\text { Wattebausch } \\
\text { (23 Versuche) }\end{array}$ & $\begin{array}{c}\text { Bürsten } \\
\text { (20 Versuche) }\end{array}$ & $\begin{array}{c}\text { Summa } \\
\text { (65 Versuche) }\end{array}$ \\
\hline o Keime & $9 \times=40.9 \%$ & $13 x=56.5 \%$ & $6 x=30 \%$ & $28 x=43 \cdot 1 \%$ \\
\hline$<100$ Keime & $9 x=40.9$ & $9 x=39 \cdot 1$ & $8 x=40$ & $26 x=40.0$ \\
\hline 100 und mehr Keime & $4 x=18.2$ & $1 \times=4.9$ & $6 x=30$ & $11 x=16 \cdot 9$ \\
\hline
\end{tabular}

Tabelle 27b.

Starke Infektion mit Colibazillen (G'emisch friseh gezüchteter Kulturen). Waschung 2 Min. in $2^{1 / 2}$ proz. $\beta$-Lysollösung.

\begin{tabular}{|c|c|c|c|c|}
\hline Es ergab: & $\begin{array}{c}\text { Einfaches } \\
\text { Waschen } \\
\text { (12 Versuche) }\end{array}$ & $\begin{array}{l}\text { Abreiben mit } \\
\text { Wattebausch } \\
\text { (12 Versuche) }\end{array}$ & $\begin{array}{c}\text { Bürsten } \\
\text { (12 Versuche) }\end{array}$ & $\begin{array}{c}\text { Summa } \\
\text { (36 Versuche) }\end{array}$ \\
\hline $\begin{array}{l}0 \text { Keime } \\
<100 \text { Keime } \\
100 \text { und mehr Keime }\end{array}$ & $\begin{array}{l}3 x=25 \% \\
2 x=16.7 \\
7 x=58.3\end{array}$ & $\begin{array}{l}4 x=33.3 \% \\
5 \times=41 \cdot 7 \\
3 \times=25\end{array}$ & $\begin{array}{l}3 x=25 \% \\
8 x=66 \cdot 7 \\
1 x=8 \cdot 3\end{array}$ & $\begin{array}{l}10 x=27.8 \% \\
15 \times=41.7 \\
11 \times=30.5\end{array}$ \\
\hline
\end{tabular}

Die Versuchspersonen wechselten regelmäßig miteinander.

Die Ergebnisse dieser Versuchsreiben sind aber lange nicht so eindeutig ausgefallen, wie beim Alkohol. Zunnächst waren bei der ersten Versuchsreihe (Tabelle 27a) die benutzten Colibazillen weniger widerstandsfähig, wie bei den meisten der früheren Versuche mit den gleichen Kresollösungen; daher erscheint die Wirkung der Mittel günstiger als sonst im 
Durchschnitt unserer Versuche. Was nun aber den Vergleich der einfachen Waschung mit der Anwendung von Bürste oder Watte betrifft, so scheint in der einen Versuchsreihe die Anwendung der Bürste etwas bessere Resultate zu geben, in der anderen dagegen das Abreiben mit Watte.

Wir können aus den Versuchen wohl nur so viel schljeßen, daB die Unterschiede nicht groß genug sind, um sich unzweideutig nachweisen zu lassen. Danach dürfen wir annehmen, daB für die Praxis die Anwendung einer Bürste, die in vielen Fällen, insbesondere in der Wohnung eines Kranken oder Bazillenträgers sclion wegen der Schwierigkeit der Bürstenreinigung, unbequem ist, zum mindesten keinen Vorteil bietet.

Das Ergebnis ist zunächst gewiß überraschend, da bei der gewöhnlichen Händereinigung, besonders bezüglich der Beseitigung des Nagelschmutzes die gute Wirkung der Bürste so augenfällig ist. Bei bakteriellen Infektionen liegt aber die Schwierigkeit der Desinfektion nicht in den groben sichtbaren Schmutzteilchen, sondern in der versteckten Lage der Keime innerhalb mikroskopisch enger Spalten; hier versagt offenbar die Wirkung der Bürste.

\section{Läßt sich die Wirkung der Desinfektion durch vorhergehende Seifenwaschung rerbessern?}

Wir wählten zur Beantwortung dieser Frage Verfahren, dië sonst keine ganz befriedigenden Resultate ergeben, um zu sehen, ob sich durch eine vorhergehende Seifenwaschung eine deutliche Verbesserung der Ergebnisse erzielen läßt. Von vornherein konnte man hoffen, daß dies der Fall sein würde. Vermindert doch das einfache Waschen die Keimzahl bereits sehr stark, so daß möglicherweise die Hände alsdann ebenso beeinflußt werden könnten, wie sonst bei einer viel schwächeren Infektion. Wie die nachfolgende Tabelle zeigt, ist das aber durchaus nicht der Fall.

Tabelle 28.

Desinfektion stark mit Bact. coli infizierter Hände durch 2 Min. langes Waschen in 2 bis 3 proz. Lösungen ron Lysol, $\beta$-Lysol, Kresotinkresol (die in ihrer Desinfektionskraft nicht sehr stark abweichen) teils mit, teils ohne vorhergehende 2 Min. lange

Seifenwaschung.

Zahl der Colikolonien nach der Desinfektion:

\begin{tabular}{ll||c|c|c}
\hline & $0-10$ & $10-100$ & über 100 \\
\hline \hline a) bei Desinfektion ohne Waschen $(44$ & Versuche) & 8 & 13 & 23 \\
b) desgl. mit Seifenwaschung $(22 \quad, \quad)$ & 0 & 6 & 16
\end{tabular}


Bei vorhergehender Seifenwaschung sind vielmehr die Resultate, die wir mit 2 bis 3prozentigen Lösungen von Kresolen erzielten, nicht besser, sondern sehlechter als ohne Waschung. Durch das Waschen werden zunächst die oberflächlich sitzenden Keime zum groben Teil entfernt; diese sind aber auch durch die chemische Desinfektion sehr leicht abzutöten, während die in den tiefen Spalten sitzenden Keime, die dem Desinfiziens schwer zugänglich sind, durch die Seifenwaschung nicht erreicht werden. Wenn nach unseren Versuchen stark infizicrte Hände durchschnittlich viel schwerer zu desinfizieren sind; als schwach infizierte, so beruht das nicht darauf, dab im ersten Falle das Desinfiziens eine verhältnismäßig dicke Schicht von Bakterien durchdringen muß, sondern darauf, daß bei 100 oder 1000 mal stärkerer Infektion die Wahrscheinlichkeit entsprechend wächst, daß Keime ganz tief in die Hautspalten hineingelangen, wo sie für das Desinfiziens unzugänglich sind.

In unseren Versuchen wirkt die Waschung augenscheinlich sogar ungünstig, indem das Desinfiziens durch die Durchfeuchtung verdünnt wird, ehe es in die Tiefe gelangt. (Daß im Gegensatze hierzu bei Anwendung absoluten Alkohols eine vorherige Durehfenchtung der Haut notwendig ist, wurde oben auseinandergesetzt.)

Schon Flügge hat darauf hingewiesen, daß die vielfach übliche und früher auch in amtlichen Vorschriften empfohlene Methode infizierte Hände zunächst mit Seife und Bürste und dann erst mit einer Desinfektionslösung zu bearbeiten, verkehrt ist, da dabei zunächst eine unberechenbare Verstreuung von infektiösen Keimen eintritt. Unsere Versuche zeigen, daß dadurch wider Erwarten nicht einmal die Wirkung der Desinfektion verbessert wird.

\section{V. Über Keimbeseitigung durch Waschen infizierter Hände mit Seife und Seifenersatzmitteln.}

Nach den in Tabelle 2 bis 4 mitgeteilten Versuchen ist die Wirkung des Waschens mit Seife auf die infizierte Hand sehr mangelhaft. Für jeden, der solche Versuche zum ersten Male macht, ist es gewiß überraschend zu sehen, daB Bazillen, die unmittelbar vorher in einem kleinen Flüssigkeitstöpfehen auf die Fingerkuppen gebracht werden, dureh energisches Waschen und Bürsten mit Seife und Nachspülen der Hände in reinem Wasser so gut wie niemals sich vollständig entfernen lassen, daß vielmebr von der frischgewaschenen, anscheinend völlig sauberen Hand meist hunderte, oft tausende von Keimen in den Agar übergehen. Auch keim Ausdrücken der Finger in Agar erschöpft sich der Keimgehalt nicht etwa bald, sondern es werden 
bei cmeutem Ausdrücken der Fingerspitzen oft noch längere Zeit hindurch immer wieder zahlreiche Keime an den flüssigen Nährboden abgegeben. Ein Beispiel hierfür bietet der folgende Versuch (Tabelle 29). Allmählich nimmt allerdings der Keimgehalt ab; wir kommen darauf später zurück.

T'abelle 29.

Ersch öpfungsversuche.

MäBig starke Infektion mit Bact, coli, danach Ausaat vołn selben Finger bzw. derselben Hand nach verschiedenen Zeiträumen.

\begin{tabular}{l|r|r|r|r|r|r|}
\hline & $\begin{array}{r}\text { Sofort } \\
\text { Kol. }\end{array}$ & $\begin{array}{r}\text { nach 1 } \\
\text { Kol. }\end{array}$ & $\begin{array}{c}\text { nach 2 } \\
\text { Kol. }\end{array}$ & $\begin{array}{c}\text { nach 3 } \\
\text { Kol. }\end{array}$ & $\begin{array}{r}\text { nach 4 } \\
\text { Kol. }\end{array}$ & $\begin{array}{l}\text { nach 10' } \\
\text { Kol. }\end{array}$ \\
\hline B. Ein Finger der rechten Hand & 50 & 30 & 5 & 20 & 10 & 0 \\
Ganze linke Hand & 100 & 800 & 800 & 300 & 300 & 100 \\
K. Ein Finger der linken Hnnd & 500 & 200 & 70 & 40 & 20 & 0 \\
Ganze rechte Hand & 2000 & 1000 & 500 & 300 & 300 & 80
\end{tabular}

Einen güinstigeren Eindruck von der Wirkung der Seife erhält man jedoch, wenn man den Keimgehalt oder vielmehr die Keimabgabe der infizierten Hände vor und nach der Seifenwaschung bestimmt und danach die Keimverminderung berechnet. Auf diese Weise erhält man ein genaueres Bild von den Leistungen der Seifenwaschung; die oben benutzte Methode, bei der meist nur die keimfreien Hände sowie die Hände mit 10, 100 usw. Keimen gezählt wurden, eignet sich wohl für stark wirkende Desinfizientien, aber nicht für dic einfache Waschung, auch dann nicht, wenn man die Infektion erheblich schwächer nimmt; in diesem Falle erscheinen häıfig die Kontrollplatten schon kcimfrei.

Wir haben nun in der genannten Weise die Wirkung einer guten (noch aus Friedenszeiten stammenden) Toilettenseife, eines Kriegsersatzmittels (Tonwaschmittel ohne Seifengehalt), eines Gipspulvers (feinster Alabastergjps), sowie der einfachen Waschung mit flieBendem Wasser verglichen. Die gute reinigende Wirkung von Ton und Lchm hat schon Bechhold erwähnt und durch Adsorption der Schmutzteilchen erklärt; neuerdings hat Gocht das Waschen mit feinem Gips als vorzüglich erprob: und speziell als Vorbereitung für die Alkoholdesinfektion empfohlen.

Wir benutzten immer eine ziemlich schwache Infektion. Eine ColiKultur wurde in $5 \mathrm{ccm} 1: 6$ mit Kochsalzlösung verdünnter Bouillon abgeschwemmt, davon 10 Tropfen in $100 \mathrm{ccm}$ derselben Verdünnungsflüssigkeit verteilt und hiervon 2 bis 4 Tropfen zwischen den Fingerspitzen beider Hände verrieben, die vorher zwecks Beseitigung der Hautkeime mit AJkohol abgerieben waren. Nach kurzem, etwa zwei Minuten langem Antrocknen wurde von einem Finger jeder Hand eine Probeaussaat in flüssigen 
Drigalskiagar gemacht, dann die Hände mit dem betreffenden Mittel zwei Minuten lang in fließendem kaIten Wasser gewaschen, an sterilen Tüchern getrocknet und wiederum, nunmehr aber sämtliche Finger, etwa $3 / 4$ Minuten lang in flüssigen Drigalskiagar ausgedrückt. Die Keimzahl der Hand vor der Desinfektion ist in allen nachfolgenden Tabellen durch Multiplikation der von einem Finger erhalten en Zahl mit 5 gewonnen.

Die Ergebnisse gerade dieser Versuche fielen sehr wechselnd aus; die Schwankungen waren viel größer als bei den chemischen Desinfektionsverfahren. Dies zeigt die nachfolgende Tabelle, bei der wir von jedem der vier verschiedenen Verfahren zuerst je zwei gut ausgefallene Versuche wiedergeben, und zwar einen mit hoher und einen mit niedriger Anfangskeimzahl, sodann zwei entsprechende, besonders schlecht ansgefallene Versuche.

Tabelle 30.

Reinigung mit Bact. coli infizierter Hände.

Einzelversuche.

Beispiele für gute und schlechte Ergebnisse.

\begin{tabular}{c}
\hline Waschen mit \\
vorher
\end{tabular}

Tabelle 31.

Reinigung mit Bact. coli schwach infizierter Hände. (169 Versuche.) Erste Art der Berechnung.

Die Behandlung mit Gipspulver ergab einen durchschnittl. Keimrest von 5.7 Proz.

\begin{tabular}{|c|c|c|c|c|c|c|c|c|c|}
\hline$"$ & " & " & Seife & , & " & $\eta$ & " & $n$ & $8 \cdot 1$ \\
\hline$"$ & $"$ & , & Tonseife & , & $n$ & $\because$ & $\eta$ & $"$ & $14 \cdot 2$ \\
\hline$n$ & $n$ & $n$ & Wasser & $n$ & , & $"$ & $"$ & $n$ & $16 \cdot 3$ \\
\hline
\end{tabular}

Zweite Art der Berechnung.

\begin{tabular}{l||c|c|c|c}
\hline Es ergab einen Keimrest & Gipspulver & Seife & Tonseife & Wasser \\
\hline Unter 1 Proz. (gut) & $9=32 \cdot 1 \%$ & $14=\mathbf{2 2 . 2} \%$ & $9=18 \cdot 8 \%$ & $3=10.0^{\circ} \%$ \\
1-10 Proz. (mittel) & $15=\mathbf{5 3 . 6}$ & $\mathbf{3 3 = 5 2 . 4}$ & $\mathbf{2 3 = 4 7 . 9}$ & $13=43.3$ \\
Über 10 Proz. (schlecht) & $4=\mathbf{1 4 . 3}$ & $16=\mathbf{2 5 . 4}$ & $\mathbf{1 6 = 3 3 . 3}$ & $14=46.7$
\end{tabular}


Bei so stark schwankendem Ausfall ist natürlich nur aus zahlreichen Versuchen ein Urteil zu gewinnen und auch dani muß man daranf verzichten, feinere Unterschiede feststellen zu wollen. Die Zahlen der nachstehenden Tabelle, die 169 Versuche umfaßt, sind aber wohl groß genug, um Zufälligkeiten einigermaßen zurïcktreten zu lassen (Tabelle 31).

Daß übrigens bei diesen Versuchen die individuellen Unterschiede der einzelnen Versuchspersonen keine große Rolle spielen, sondern linter den sonstigen Zufälligkeiten ganz zurücktreten, zeigt die Tabelle 32.

Tabelle 32.

Erste Art der Berechnung.

Der durchschnittliche Keimrest bei Dr. N. betrug 11.5 Prozent

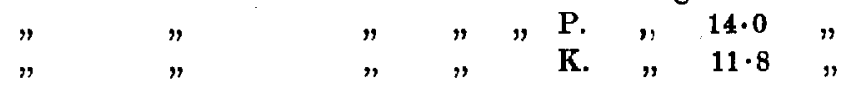

Zweite Art der Berechnung.

\begin{tabular}{|c|c|c|c|}
\hline Es ergab einen Keimrest & Dr. N. & Dr. $\mathbf{P}$. & K. (Labor. Angestellter) \\
\hline $\begin{array}{l}\text { Unter } 1 \text { Proz. (gut) } \\
\text { 1-10 Proz. (mittel) } \\
\text { Úber } 10 \text { Proz. (schlecht) }\end{array}$ & $\begin{aligned} 5 & =9.4 \% \\
32 & =60.4 \\
16 & =30.2\end{aligned}$ & $\begin{aligned} 2 & =10 \% \\
7 & =35 \\
11 & =55\end{aligned}$ & $\begin{aligned} 8 & =19 \% \\
21 & =50 \\
13 & =31\end{aligned}$ \\
\hline
\end{tabular}

Wir haben den Erfolg der verschiedenen Verfahren auf zweierlei Art bestimmt. Zunächst in der Weise, daß wir bei jedem Einzelversuch die Prozentzahl der Keimabnahme ermittelt und darauf den Durchschnitt dieser Prozentzahlen berechnet haben. Ergibt sich wie bisweilen anstatt der Keimabnahme eine Zunahme, so muß der Keimrest natürlich gleich 100 Prozent gesetzt werden, da das Ergebnis sonst paradox wäre.

Daneben haben wir die Ergebnisse noch in der Weise zusammengestellt, daß wir wieder für jeden Versuch die prozentuale Keimabnahme berechneten und die Versuche danach in drei Gruppen einteilten, wobei wir Versuche, bei denen weniger als 1 Prozent. Keime übrigblieben, als gut bezeichnet haben, solche mit einem Ergebnis zwischen 1 und 10 Prozent als mittel und solche mit einem Keimrest uiber 10 Prozent als schlecht.

Die Versuche zeigen zunächst, daB in allen Fällen eine schr erhebliche Keimverminderung eintrat, die praktisch sicher von großer Bedeutung ist; sie schwankt bei den einzelnen Verfahren zwischen 84 und 94 Prozent. $\Lambda \mathrm{m}$ besten wirkte das Gipspulver, demnächst die Scife, dann folgt das Tonwaschmittel und zuletzt das einfache Waschen mit Wasser. Die Wirkung der letzten beiden Verfahren ist nicht unbeträchtlich schlechter 
als die der ersten. Immerhin sind die Unterschiede nicht so grob, wie man von vornherein vermuten sollte und vor allem ist überraschend, da $B$ die Seife weniger gut als das Gipspulver wirkt; hat man doch nach dem Waschen mit Seife ein besonderes Gefühl der Reinigung, wenigstens dann, wenn es sich um fettige Verunreinigungen handelt. Es zeigt sich also wieder, daß die Entfernung von Bakterien aus den Hautspalten ganz anderen Bedingungen unterliegt, wie die Entfernung von Fetteilchen, und daß die Schwierigkeit, keimfreie Hände zu erzielen, nicht auf der Einbettung der Bakterien in fetthaltigen Schichten beruht.

Nach unseren Versuchen braucht daher vom hygienischen Standpunkt der durch die Kriegsverhältnisse bedingte Mangel an . Seife keinen erheblichen Nachteil zu bedeuten, wenigstens nicht unmittelbar. Mittelbar möchten wir allerdings einen ungünstigen Eindruck annehmen, da eine gute Seife im Gebrauch viel angenehmer ist, die sichtbaren Schmutzteilchen wegnimmt und damit ein ganz anderes subjektives Gefühl der Reinheit hinterläßt als das Waschen mit Tonwaschmittel oder gar das Waschen mit reinem Wasser. Dieser Gesichtspunkt ist praktisch sehr zu beachten; gewiß nimmt beim Mangel an Seife allgemein die Neigung $a b$, sich häufiger und besonders sich lange und gründlich zu waschen. Schon das Abspülen des Seifenschaums veranlaßt zu längerem Waschen, vor allem aber hat man beim Waschen ohne Seife nicht wie beim Seifenwaschen das Gefülıl, alle Unreinlichkeiten von den Händen los zu werden. Aus solchen praktischen Gründen wird auch der Ersatz der Seife durch Gips zu empfehlen sein; wir haben also vom hygienischen Standpunkt aus ein erhebliches Interesse an guten Seifenersatzmitteln.

Das Gipspulver hat nun aber den großen Vorzug, daß es beim Waschen angenehm ist, jedenfalls fanden wir es weit angenehmer, als die in festen Stücken in den Fandel gebrachten Tonwaschmittel. Auch entfernt der Gips sichtbare Unreinlichkeiten. der Haut recht gut und man ist, schon um das Pulver zu entfernen, gezwungen, sich etwas länger zu waschen. Schïttet man einen kleinen Löffel Gips in die angefeuchtete Hohlhand und rührt daas Palver zunächst mit etwas Wasser an, so läßt sich cine Verstreuung von Gips anf. die Rockärmel usw. vermeiden und der Gips überzieht als feine Paste die ganze Hand. Zweckmäßig würde es sein, den Gips in einem weithalsigen Gefäß mit einem Löffel darin auf dem Waschtisch stehen zu lassen. (Nicht etwa in einer Streubüchse, da man sich dann die Kleider leicht mit Gipsstaub verunreinigt.) Auch kann man, wie Bechhold es als eine Gewohnheit der Spengler beschreibt, die feuchten Hände in einen Topf mit Gips tauchen; man erhält dann besonders leicht einen foinen pastenartigen Utberzug von Gips, ohne das Pulver zu verstreuen. 
Die angegebene Eigenschaft des Gipses, vor allem auch das subjektive Gefühl der Reinigungswirkung, ist u. E. praktisch von großer Bedeutung; wir können daher vom ärztlichen Standpunkt aus den Gebrauch von Gipspulver - wenigstens 2 Teelöffel für jede Waschung - als Seifenersatz nur empfehlen.

Wenn der Gips in unseren Versuchen besser als Tonseife wirkt, so liegt das zweifellos hauptsächlich daran, daß er viel feineres Korn und daher stärkere Adsorptionswirkung hat. Außerdem geben die festen Tonwaschmittel nicht genügend von dem Material an die fouchte Hand ab. In zahlreichen Versuchen haben wir später neben dem Alabastergips auch gewöhnlichen Gips. (der ebenso wie der Alabastergips gebrannter Gips ist, das heißt chemisch das Halbhydrat des Kalziumsulfats), sowie den unter dem Namen Lenzin ${ }^{1}$ im Handel erhältlichen ungebrannten Gips (das Hydrat $\mathrm{CaSO}_{4}{ }^{\cdot}$ $2 \mathrm{H}_{2} \mathrm{O}$ ) benutzt. Die Mittel sind billiger als Alabastergips und wir habei weder bezïglich der Reinigungswirkung noch bezüglich der Entfermung von Bakterien Unterschiede zwischen ihnen und dem Alabastergips feststellen können; es kommt offenbar nur auf das feine Korn an. Wir möchten daher insbesondere diese einfachen Gipspulver zur allgemeinen Anwendung als Seifenersatz empfehlen.

Ähnlieh wie bej den oben mitgeteilten Versuchen mit Betalysol haben wir auch bei dem einfachen Waschen mit Seife geprift, ob sich das Ergebnis durch Anwendung einer Bürste verbessern läßt, wie man das wohl-von vornherein erwartet und wie es wohl bisher meist als selbstverständlich angenonmen ist. Auch hier zeigte sich aber bei einigen Versuchen durch Anwendung einer Bürste zum mindesten keine deutliche Verbesserung der Wirking.

Für die Händedesinfektion am Krankenbett bei Bazillenträgern usw. solite man danach für die Fälle, wo aus praktischen Gründen anstatt einer Desinfektion eine einfache Rẹinigung der Hände vorgenommen wird, auf den Gebrauch einer Bürste verzichten, wobei man zugleich der schwierigen Frage der Desinfektion der infizierten Bürsten aus dem Wege geht.

Wir haben nun noch cine klejne Versuchsreihe mit coliversetzten sterilisierten Fäzes gemacht, um festzustellen, ob sich bei diescr der natürlichen Infektion mehr entsprechenden Versuchsanordnung etwa der Einflu $B$ der Seife oder der Bürste in anderer Weise geltend macht, wie bei den Versuchen mit wässerigen Abschwemmungen von Colibazillen.

${ }^{1}$ Preis $1 \mathrm{~kg}$ (GroBpreia) $10 \mathrm{Pfg}$, Einzelverkauf $20 \mathrm{Pfg}$. 
Tabelle 33 .

Die Fingerapitzen werden mit Füzes infiziert, die sterilisiert und dann schwach mit Bact. coli versetzt sind. Danach 2 Min. lang Wasehen mit Wasser bzw. Seife und Bürste. Je 10 Versuche.

Berechnung $\mathrm{I}$.

Nach Waschen mit Wasser ergab sich ein Keimrest von durchschnittl. 4.7 Proz.

$" \quad "$ Seife u. Bürste " " " " $\quad 9 \cdot 35$ "

Berechnung II.

\begin{tabular}{l||c|c}
\hline \multicolumn{1}{c|}{$\begin{array}{c}\text { Es ergab einen durchschnittlichen } \\
\text { Keimrest von }\end{array}$} & $\begin{array}{c}\text { Waschen mit } \\
\text { Wasser (10 Vers.) }\end{array}$ & $\begin{array}{c}\text { Waschen mit Seife } \\
\text { u. Bürste (10 Vers.) }\end{array}$ \\
\hline \hline Unter 1 Prozent (gut) & $\begin{array}{l}4=40 \% \\
10 \text { Prozent (mittel) }\end{array}$ & $\begin{array}{c}4=40 \\
\text { 1-10 }\end{array}$ \\
mehr als 10 Prozent (schlecht) & $2=20$ & $7=70 \%$ \\
\hline
\end{tabular}

Wie die Tabelle zeigt, läßt sich auch hier zum mindesten eine wesentliche Uberlegenheit der Seife und der Bürste nicht feststellen; dab das Bürsten mit Seife sogar schlechter wirkte als einfaches Waschen in fließendem Wasser, ist bei der geringen Zahl der Versuche gewiß als Zufall anzusehen.

\section{VI. Über den Schutz der Hände dureh vorhergehende Waschung mit Sublimat (Sublamin, Quecksilberoxycyanid).}

Da es nach den mitgeteilten Versuchen nur recht schwer gelingt, infektiöse Keime, die auf die Hand geraten sind, vollständig zu beseitigen, so erscheint es um so wichtiger, die Infektion der Finger nach Möglichkeit am Krạnkenbett in ähnlicher Weise zu vermeiden, wie es der Chirurg vermeidet, seine Hände mit septischen Keimen zu verunreinigen. Nun hat Speck in Flügges Laboratorium entdeekt, da $B$ an einer mit Sublimat gewaschenen Hand später aufgebrachte Colibazillen abgetötet werden und auf Grund seiner Versuche die vorhergehende Waschung mit Sublimat für die Praxis empfohlen. Dieses vorzügliche Verfahren ist noch nicht genügend bekannt geworden, und da auch Speck nur wenige Versuche mitgeteilt hat, so haben wir einige größere Versuchsreihen angestellt, die überraschend gute Ergebnisse lieferten.

Eine Stunde nach Sublimatwaschung wurden in einer Reihe von 60 Versuchen die Hände nit einer mittelstarken Abschwemmung von Colibazillen infiziert. Sobald die Kultur angetrocknet war, wurde in der üblichen Weise eine Entnahme gemacht. In 88.3 Prozent der Fälle kamen keine Colibazillen mehr zur Entwicklung, in 10 Prozent waren es unter 
100 und nur in 1.7 Prozent über 100 Keime. Dic Wirkung des Sublimats hält deutlich sogar noch nach 24 Stunden an, wo bei derselben Versuchsanordnung die Colibazillen in 50 Prozent der Fälle noch vollständig abgetötet wurden. Die genauen Zahlen sind aus der Tabelle ersichtlich.

Tabelle 34.

Nachwirkung von $0 \cdot 1$ prozentiger Sublimatlösung.

Waschen mit 0.1 proz. Sublimat; abtrocknen mit Gaze; verschieden lange Zeit danach werden die Finger mit Bact. coli mittelstark infiziert und nach Antrocknen der Kultux, d. h. nach etwa 2 Min., in Drigalskiagar ausgedrückt.

\begin{tabular}{|c|c|c|c|c|}
\hline Dann ergaben: & $\underset{(60 \text { Vers. })}{\text { nach } 1 \text { Std. }}$ & $\begin{array}{c}\text { nach } 2 \text { Std. } \\
\text { (8 Vers.) }\end{array}$ & $\begin{array}{c}\text { nach } 24 \text { Std. } \\
\text { (66 Vers.) }\end{array}$ & $\begin{array}{l}\text { nach } 48 \text { Std. } \\
\text { (12 Vers.) }\end{array}$ \\
\hline 0 Coli & $53=88.3 \%$ & $7=87.5 \%$ & $33=50 \cdot 0 \%$ & - \\
\hline Unter 100 Coli & $6=10 \cdot 0$ & $1=12 \cdot 5$ & $17=25 \cdot 8$ & - \\
\hline Über 100 Coli & $1=1 \cdot 7$ & - & $16=24 \cdot 2$ & $12=100 \%$ \\
\hline
\end{tabular}

Individuelle Verschiedenheiten bei Sublimatnachwirkung.

\begin{tabular}{|c|c|c|c|c|}
\hline & $\mathbf{K}$. & Sp. & Sff. & $\mathrm{Br}$. \\
\hline Nach & $\begin{array}{l}\text { In } 10 \text { Versuchen: } \\
7 \times 0 \mathrm{Keime}\end{array}$ & $\begin{array}{l}\text { In } 10 \text { Versuchen: } \\
10 \times 0 \text { Keime }\end{array}$ & $\begin{array}{l}\text { In } 10 \text { Versuchen: } \\
6 \times 0 \text { Keime }\end{array}$ & $\begin{array}{l}\text { In } 10 \text { Versuchen } \\
10 \times 0 \text { Keime }\end{array}$ \\
\hline 1 Stunde & $\begin{array}{l}2 \times 2 \\
1 \times 100 "\end{array}$ & & $4 \times$ unter $100 \mathrm{~K}$. & \\
\hline
\end{tabular}

Nachwirkang ron 1 proz. Quecksilberoxycyanid- und 1 proz. Sublaminlösung.

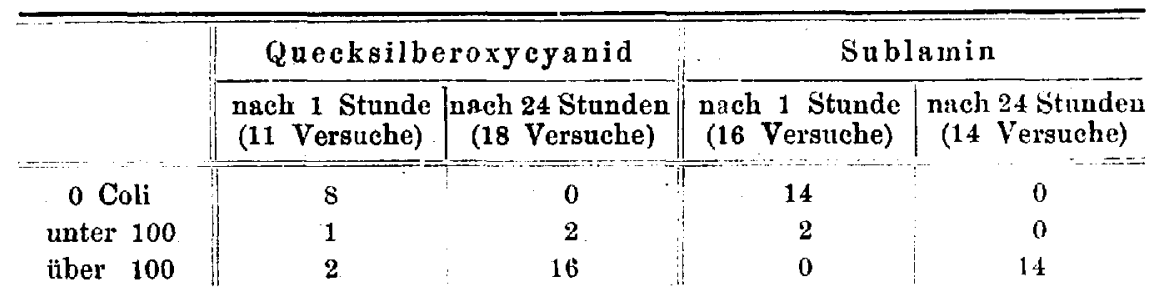

Nachwirkungsversuch mit 5prozentiger Lysollösung.

\begin{tabular}{|c|c|c|c|c|c|c|}
\hline & \multicolumn{2}{|c|}{ K. } & \multicolumn{2}{|c|}{ R. } & \multicolumn{2}{|c|}{ B. } \\
\hline & r. & 1. & r. & 1. & r. & 1. \\
\hline Nach 5 Minuten & 0 & 0 & 1 & $\mathbf{1}$ & 0 & 0 \\
\hline Nach $1 / 2$ Stunde & 150 & 100 & $\infty$ & $\infty$ & 500 & 500 \\
\hline
\end{tabular}


Auch hier spielen individuelle Verschiedenheiten eine Rolle; wir hatten Versuchspersonen, bei denen sich sowohl eine Stunde, als auch 24 Stunden nach der Sublimatwaschung niemals Colibazillen entwickelten (z. B. Frl. Sp. in der Tabelle) und wieder andere, die wesentlich schlechtere Ergebnisse hatten. Ein analoger Versuch mit 5 Prozent Lysol zeigte 5 Minuten nach der Waschung einen starken EinfluB des Mittels, aber nicht mehr eine halbe Stunde danach. Diese bisher noch nicht genügend bekannte Nachwirkung des Sublimats sollte in möglichst großem Umfange, insbesondere von deń Wartepersonal auf Infektionsabteilungen, aber auch von Ärzten ausgenutzt werden.

Auch Sublamin und Quecksilberoxycyanid haben eine ausgezeichnete Nachwirkung; sie kommen darin allerdings dem Sublimat lange nicht gleich, wie besonders die Ergebnisse nach 24 Stunden zeigen. Die individuellen Untersehiede waren bei beiden Mitteln deutlich erkennbar.

\section{VII. Über Desinfektion von Sitzbrettern.}

Auf Grund der bei der Händedesinfektion gemachten Erfahrungen mit Sublimat und Lysol machten wir einige Versuche iiber die Wirkung beider Mittel an mit Bact. coli infizierten Brettern. Für die Desinfektion der Abortsitzbretter ist bisher 5prozentige Kresolseifenlösung vorgeschrieben; wir haben nun erstens versucht, ob nicht auch hier Sublimat weit besser wirkt und ob zweitens das Mittel sich ähnlich wie in der Haut, so auch in dem Holz speichert, so daß cine später erfolgende Infektion, z. B. mit einem Tropfen Typhusurin oder mit verspritztem flüssigem Stuhlgang, unschädlich gemacht wird; eine Desinfektion dickerer Fäzessehichten wird man natürlich nicht erwarten können. In der Tat zeigte das Sublimat eine recht starke derartige Nachwirkmg und es erwics sich ferner als weit wirksamer als 5 prozentiges Lysol, so daß es zur Desinfektion von Abortsitzbrettern um so molur den Vorzug verdient, als gerado hier der unangenehme Kresolgeruch sehr störend ist. Dasselbe gilt für Fußböden.

Die Versuchsanordnung bei unseren Versuchen über Sitzbrettdesinfektion war die folgende: das Holz wurde zunächst mit Wasser und 96 prozentigen Alkohol abgerieben. Daranf wurde auf drei verschiedene Stellen desselben je 1 Tropfen einer Coli-Bouillonkultur ans einer Pipette getropft und verrieben. 5. Minuten darauf wurden zwei von den Stellen mit $0 \cdot 1$ prozentigen Sublimat bzw. 5prozentigem Lysol mittels sterilen Läppchen abgerieben; eine Aussaat erfolgt 5 Minuten und 1/2 Stunde nach der Desinfektion von den desinfizierten und der Kontrollstelle in der Weise, daB mit dem Finger oder mit einem sterilen, angefeuchteten Gazeläppchen 10 Sekunden lang über die Holzstelle gerieben wurde. Der Finger bzw. das Läppchen wurde darauf in flïssigem Drigalskiagar ausgedrückt. 
Die Anordnung der Versuche, in denen die Nachwirkung von Sublimat und Lysol auf Sitzbrettern untersucht wurde, war ähnlich. Hierbei wurden zuerst mehrere Stellen des Holzes mit Sublimat- bzw. Lysollösungen abgerieben, darauf die einzelnen Stellen in verschiedenen Zeiträumen $(1 / 2,1,2$, 24 Stunden usw. nach dem Abreiben mit dem Desinfiziens) mit einem Tropfen Colibouillon infiziert. Die Aussaat erfolgte 5 Minuten nach der jeweiligen Infektion in der oben geschilderten Weise.

Tabelle 35.

Beispiel eines Desinfektionsversuches von 2 Holzarten.

Die Desinfektion erfolgte 5 Minuten nach der Infektion mit Bact. coli; die Aussauten 5 und 30 Minuten nach der Desinfektion.

\begin{tabular}{|c|c|c|c|c|}
\hline & $\begin{array}{r}\text { Poliert } \\
\text { Nach } 5 \text { Min. }\end{array}$ & $\begin{array}{l}\text { Solz } \\
\text { Nach } 1 /, \text { Std. }\end{array}$ & $\begin{array}{r}\text { Rauh } \\
\text { Nach } 5 \text { Min. }\end{array}$ & $\begin{array}{l}\mathrm{Holz} \\
\mathrm{Nach} 1 / 2 \text { Std. }\end{array}$ \\
\hline Sublimat 0.1 Prozent & 0 Keime & 0 Keime & 0 Keime & 0 Keime \\
\hline Iysol 5 Prozent & $0 \quad "$ & $0 \quad "$ & $2000 n$ & \\
\hline Kontrolle ohne Desinfiziens & $\infty$ & 0 & $\infty \quad n$ & $\infty$ \\
\hline
\end{tabular}

Beispiel eines Versuches auf 2 Holzarten mit Infektion za verschiedenen Zeiträumen nach der Waschung mit dem Desinfiziens.

\begin{tabular}{|c|c|c|c|c|c|}
\hline & \multicolumn{5}{|c|}{ Poliertes Holz } \\
\hline & $\begin{array}{c}\text { Infektion } \\
\text { nach } 1 \text { Std. }\end{array}$ & $\begin{array}{c}\text { Infektion } \\
\text { nach } 2 \text { Std }\end{array}$ & $\begin{array}{c}\text { Infektion } \\
\text { nach } 3 \text { Std. }\end{array}$ & $\begin{array}{c}\text { Infektion } \\
\text { nach 5 Std. }\end{array}$ & $\begin{array}{c}\text { Infektion } \\
\text { nach 24 Std. }\end{array}$ \\
\hline Sublimat & 10 Keime & 50 Keime & 1 Keim & 1 Keim & 1 Keim \\
\hline Lysol & $\infty \quad "$ & $\infty \quad "$ & $\infty \quad$, & $\infty \quad ;$ & $2000 "$ \\
\hline
\end{tabular}

Kontrolle ohne Desinfiziens: $\infty$ Keime.

\begin{tabular}{|c|c|c|c|c|c|}
\hline & \multicolumn{5}{|c|}{ Rauhes Holz } \\
\hline & $\begin{array}{c}\text { Infektion } \\
\text { nach 1 Std. }\end{array}$ & $\begin{array}{c}\text { Infektion } \\
\text { nach 2 Std. }\end{array}$ & $\begin{array}{c}\text { Infektion } \\
\text { nach } 3 \text { Std. }\end{array}$ & $\begin{array}{c}\text { Infektior } \\
\text { nach } 5 \text { Std. }\end{array}$ & $\begin{array}{r}\text { Infektion- } \\
\text { nach } 24 \text { Std. }\end{array}$ \\
\hline Sublimat & 300 Keime & 1000 Keime & 500 Keime & 2 Keime & $\infty$ Keime \\
\hline Lyso] & $\infty \quad$, & $\infty \quad$, & $\infty \quad "$ & $\infty \quad n$ & $\infty \quad " \quad$ \\
\hline
\end{tabular}

Kontrolle ohne Desinfiziens: $\infty$ Keime.

Bei 5 Desinfektionsversuchen an verschiedenen Holzarten waren bei poliertem Holz sowohl Sublimat als auch Lysol gut wirksam, auf nicht poliertem Holz hingegen nur Sublimat. In 5 Versuchen über die Nachwirkung war eine solche besonders auf glattem Holz beim Sublimat sehr ausgesprochen, bei Lysol dagegen nieht deutlich vorhanden. 


\section{IäBt sich durch den Gebrauch von Klosettpapier die Infektion der Hand verhüten?}

Von erheblicher praktischer Bedeutung ist die Frage, ob bei genügendem Gebrauch von Klosettpapier eine Beschmutzung der Hände mit Coljbazillen und entsprechend bei Kranken und Bazillenträgern mit Typhus oder Ruhrkeimen überhaupt einzutreten braucht. Nach unseren Versuchen ist das nicbt der Fall. Wir haben in 10 Versuchen, darunter zwei mit ganz dünnfliissigem Stuhlgang, nach Benutzung von dünnem Klosettpapier in mehrfacher Lage niemals Colibazillen an unseren Händen unmittelbar nach der Stuhlentleerung nachweisen können. Dabei wurden dic Hände ebenso wie bei den Desinfektionsversuchen in flüssigen Drigalskiagar ausgedrückt; von einer Anreicherung, etwa nach dem Verfahren von Ejkmann, haben wir absichtlich Abstand genommen, da das Vorhandensein einzelner Keime, die sich nur durch besondere Anreicherung ndchweisen lassen, unseres Erachtens praktisch bedeutungslos ist. Nicht so günstig wie unsere den praktischen Verhältnjssen angepaßten Versuche sind Versuche von Weichhardt und Haussner ausgefallen, die die Analgegend reichlich mit Prodigiosusbazillen infizierten und die Keime nach Gebrauch von Kreppapier an den Fingern nachwiesen.

Der reichliche Gebrauch von Klosettpapier, das bisher in den Merkblättern und volkstümlichen Belehrungen gar nicht erwähnt wurde, sollte als eins der wichtigsten Mittel zur Verhütung der Utbertragung von Typhus ond Ruhr empfohlen werden, wie das in der neuen Desinfektionsanweisung für Ruhr (Min.-Blatt f. Med. Ang. 1918, Nr. 14) geschehen ist. Auch in diesem Falle wird es in der Regel viel einfacher und zweckmäßiger sein, Infektionen der Finger zu verhuiten, als sie hinterher zu beseitigen.

\section{Versuche ïber den Übergang von Keimen von einer Hand auf die andere.}

Bei der Unvollkommenheit der einfachen ReinlichkeitsmaBnahmen in ihrer Wirkung auf infizierte Hände könnte es scheinen, als stimmten die praktischen Erfahrungen mit unseren Ergebnisse nicht überein, da sich doch in vielfachen Beobachtungen immer wieder gezeigt hat, dab einigermaßen reinliche Bazillenträger oft jahrelang in ihrer Familie leben, ohne jemand in ihrer Umgebung anzustecken. Ja, schon die bloße Tatsache, daB eine Person als Bazillenträger bekannt ist, bietet, wie Robert Koch mehrfach hervorgehoben hat, bereits an sich einen erheblichen Schutz. 
Zur Erklärung der relativen Ungefährlichkeit von Kranken und Bazillenträgern, wie sie uns die tägliche Beobachtung zeigt, muß man sich zunächst daran erinnern, daß von einer infiz erten Hand bei Berührungen in den meisten Fällen nur ein kleiner Bruchteil der daranhaftenden Keime abgegeben wird. Dies hat schon Ostermann in Flügges Laboratorium auch experimentell nachgewiesen; in seinen Versuchen ging beim Händedruck durchschnittlich erst von mehreren 1000 Bakterien eines auf die zweite Hand über.

Wir haben unsere Versuche in der Weise angestellt, daß wir die Fingerspitzen der einen Hand infizierten und nach kurzem Antrocknen mit den Fingern der anderen Hand 10 bis 15 Sekunden lang rieben.

Tabelle 36.

Abdruckversuche an mit Bact. coli infizierten Fingern. Infektion links, Aussaat nach 10 Sek. langem Abdrücken rechts und links gleichzeitig.

\begin{tabular}{c|c|c||c|c|c}
\hline Finger & \multicolumn{2}{|c||}{$\begin{array}{c}\text { A. Schwache Infektion } \\
\text { Kolonien } \\
\text { l. }\end{array}$} & $\begin{array}{c}\text { Kolonien } \\
\text { r. }\end{array}$ & Finger & \multicolumn{2}{c}{$\begin{array}{c}\text { B. Starke Infektion } \\
\text { Kolonien } \\
\text { l. }\end{array}$} & $\begin{array}{c}\text { Kolonien } \\
\text { r. }\end{array}$ \\
\hline 1. & 20 & 0 & 1. & 20000 & 20 \\
2. & 200 & 0 & 2. & 20000 & 1 \\
3. & 40 & 0 & 3. & 20000 & $1000^{1}$ \\
4. & 80 & 0 & 4. & 20000 & 15 \\
5. & 30 & 0 & 5. & 20000 & 5
\end{tabular}

Wie die vorstehende Tabelle in Ubereinstimmung mit Ostermanns Versuchen zeigt, gehen unter solehen Bedingungen von einem schwach infizierten Finger überhaupt keine Keime auf den reinen Finger über, während bei starker Infektion durchschnittlich erst von mehreren 1000 Keimen einer übergeht; nur in einem Falle, wo der infizierte Finger noch etwas feucht war, war das Ergebnis ungünstiger. Dabei gelten unsere Ergebnisse für die Berührung von Hand zu Hand unter ungünstigen Bedingungen, nämlich unmittelbar nach der Infektion; läßt man etwas längere Zeit verstreichen, so ist die Wahrscheinlichkeit einer Infektion, wie die unten mitgeteilten Versuche zeigen, zweifellos noch geringer. Werden trockene Nahrungsmittel; Brotkruste, ungeschältes Obst u. dgl., mit schmutzigen, aber trockenen Händen angefaßt, so dürften ähnliche Verhältnisse wie im vorigen Versuch vorliegen; kommen die Hände mit feuchten oder flüssigen Nahrungsmitteln, z. B. Kartoffelschnitten, rohem Fleisch, Milch in Berührung, oder werden sie gar, wie es beim Anrichten

${ }^{1}$ Bei diesem Versuch war der infizierte Finger noch eine Spar feucht. 
von Salat, bei der Zubereitung von Hackfleisch, von Mehlspeisen u. dgl. vorkommen kann, durch wiederholtes Drücken gewissermaßen in das flüssige oder feuchte Medium hineingepreßt, so nähern sich die Verhältnisse denen in unseren Versuchen, wo wir die infizierten Finger in flüssigem Agar auspressen. Die Erfahrung lehrt nun, daß gerade unter derartigen Bedingungen in der Tat verhältnismäßig häufig Ubertragungen von Typhus und Paratyphus durch Nahrungsmittel vorkommen.

\section{X. Über ,Selbstreinigung"6 der Hände und ihre hygienische Bedeutung.}

Ein sehr wichtiger, natürlicher Schutz gegen die Ubertragung' von Typhus, Ruhr usw. durch infizierte Finger ist aber weiterhin in einem. bisher wohl noch nicht näher untersuchten Vorgange zu sehen, den wir als Selbstreinigung der Hand bezeichnen möchten. Infiziert man nämlich die Hände mit Bact. coli und macht in derselben Weise wie bei den vorhergehenden Versuchen versehiedene Zeit nach dem Antrocknen Entnahmen von den Fingern, so sieht man, daß schon nach kurzer Zeit nur ein kleiner Bruchteil der aufgebrachten Keime abgegeben wird. Dies zeigt sehr deutlich der in der folgenden Tabelle wiedergegebene Versuch, bei dem die Keimabgabe 5 Minuten nach dem Antrocknen untersucht wurde.

\section{Tabelle 37.}

Versuch über das spontane Absterben von Colibazillen an den Fingern verschiedener Personen, Die fünf Finger einer Hand werden der Reihe nach mit je einer Öse Coliaufsehwemmung in abgestuften Verdünnungen infiziert, indem die Öse auf der Fingerkuppe bis zum Trocknen verrieben wird. 5 Minuten danach wird jeder Finger einzeln in eine Schale mit flüssigem Drigalskiagar ausgedrỉekt: Durch Kontrollaussaat wird der Keimgehalt einer Öse bestimmt.

\begin{tabular}{|c|c|c|c|c|c|c|}
\hline \multirow{2}{*}{ Finger } & \multirow{2}{*}{$\begin{array}{l}\text { Infiziert mit } \\
\text { Coli-Auf- } \\
\text { schwemmung }\end{array}$} & \multirow{2}{*}{$\begin{array}{l}\text { Kontrollaus- } \\
\text { saat der Auf- } \\
\text { sehwemmung }\end{array}$} & \multicolumn{4}{|c|}{ Entnahme nach 5 Minuten } \\
\hline & & & Dr. Sch. & Dr. $\mathbf{N}$. & Frl. Km. & $\mathbf{K} f$. \\
\hline 1. & $1: 10$ & $>50000$ & 2000 & 10000 & 0 & 0 \\
\hline 2. & $1: 100$ & 40000 & 2000 & 80 & 0 & 0 \\
\hline 3. & $1: 1000$ & 3000 & 8 & 30 & 0 & 0 \\
\hline 4. & $1: 10000$ & 1000 & 0 & 20 & 0 & 0 \\
\hline 5. & $1: 100000$ & 200 & 3 & 4 & 0 & 0 \\
\hline
\end{tabular}

Ein weiterer Versuch wird an Frl. Km. angestellt, indem eine Öse einer entsprechenden Coliverdünnung 1:100 auf jedem der. fünf Finger verrieben wird:

Aussaat nach 5 Minuten: alle 5 Finger 0 Coli! 
Begreiflicherweise verschwanden die Keime von den Fingern um so schneller, je weniger heraufgebracht wurden. Sehr auffallend ist aber die überraschend schnelle und vollständige Abtötung bei den beiden letzten Versuchspersonen; sie erklärt sich dadurch, daß dieselben sich an den vorhergehenden Tagen vielfach mit Sublimat gewaschen hatten!

Tabelle 38.

Selbstreinigungsversuch

an 17 Pexronen, deren Hände tags zuvor mit $\left(\mathrm{NH}_{4}\right)_{2} \mathrm{~S}$ gewaschen worden waren, um die Wirkung vorangegangener Sublimatwaschungen auszuschalten.

1 Colikultur wurde in $10 \mathrm{ccm}$ Kochsalalösung abgeschwemmt, dann 1 Tropfen einer Verdünnung 1:100 auf die Fingerspitzen jeder Hand verrieben. Erste Entnahme sogleich nach dem Antrocknen, zweite Entnahme 10 Minuten danach ron je 1 Finger.

Der Vergleich der Keimzahlen bei beiden Entnahmen ergibt:

Keine oder geringe Abnahme . . . . . . . 2 mal

Abnahme auf $1 / 6-1 / 10$ des Keimgehaltes . . 8 ,

$" \quad 1 / 10-1 / 100, \quad$. . . $7 "$

Tabelle 39.

Mit je 1 Tropfen verschieden stark verdünnter Aufschwemmungen werden die Fingerspitzen einer Versuchsperson infiziert.

\begin{tabular}{l|c|c|c}
\hline Versuchsperson & $\begin{array}{c}\text { Keimzahl } \\
\text { im Tropfen }\end{array}$ & $\begin{array}{c}\text { Keimzahl } \\
\text { an der Hand }\end{array}$ & $\begin{array}{c}\text { Entnahme Miuuten } \\
\text { nach } \\
\text { Antrocknung }\end{array}$ \\
\hline Dr. Dr. & $\infty$ & $\infty$ & $\mathbf{2}^{\prime}$ \\
Kl. & $\infty$ & ca. 100000 & $2^{\prime}$ \\
Pi. & 15000 & 300 & $2^{\prime}$ \\
Sch. & $>100000$ & 160 & $5^{\prime}$ \\
Fr. & $>100000$ & 400 & $5^{\prime}$ \\
Kl. & $>100000$ & 5000 & $10^{\prime}$
\end{tabular}

Der nächste Versuch zeigt, wie bei mehrfacher Untersuchung desselben Fingers die Keimzahlen allmählich abnehmen (s. Tabelle 40).

Nun ist es sicher, daß bloßes Eintrocknen die Bazillen nicht so schnell zum Absterben bringt, und es erhebt sich daher die Frage, worauf dic Selbstreinigung der Hand beruht, ob etwa vorwiegend auf mechanischer Abstobung oder auf Abtötung durch bakterienfeindliche Stoffe der Haut, wobej man entsprechend der Reaktion der Haut an Säuren denken kann. Um hierüber Auskunft zu erhalten, haben wir an denselben Personen nebeneinander Versuche mit Bact. coli und den widerstandsfähigen Hoffmannssporen gemacht (s. Tabelle 41). 
Tabelle 40.

Ein Finger der Versuchsperson wird mit einer Öse oder einem Tropfen einer dichten Coliaufschwemmung infiziert, der Tropfen wird bis zur Verdunstung verrieben. Nach bestimmter Zeit wird derselbe Finger mehrmals in flüssigem Drigalskiagar ausgedrückt. Die Hände sind lange nicht mit Sublimat in Berührung gekommen.

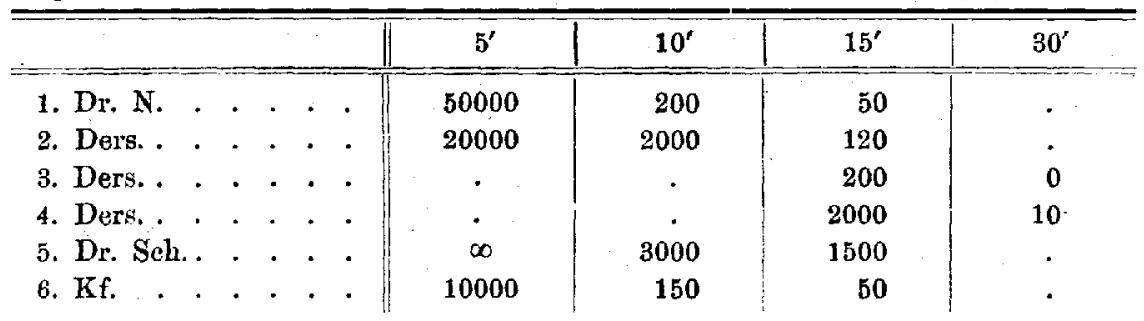

Tabelle 41.

In derselben Weise wie bei den vorhergehenden Versuchen werden die 5 Finger einer Hand mit einer 1:100 verdünten Coliabschwemmung infiziert, die Finger der anderen Hand gleichzeitig mit einer ebenso verdünnten Abschwemmnng von Hoffmannsporen. Kontrollaussaaten der Coliverdünnung ergeben etwa 20000 bis 100000 Keime, der Sporenabschwemmung (nicht genau zählbar) etwas geringeren Keimgehalt, jedenfalls mehrere tausend Kolonien in einem Tropfen.

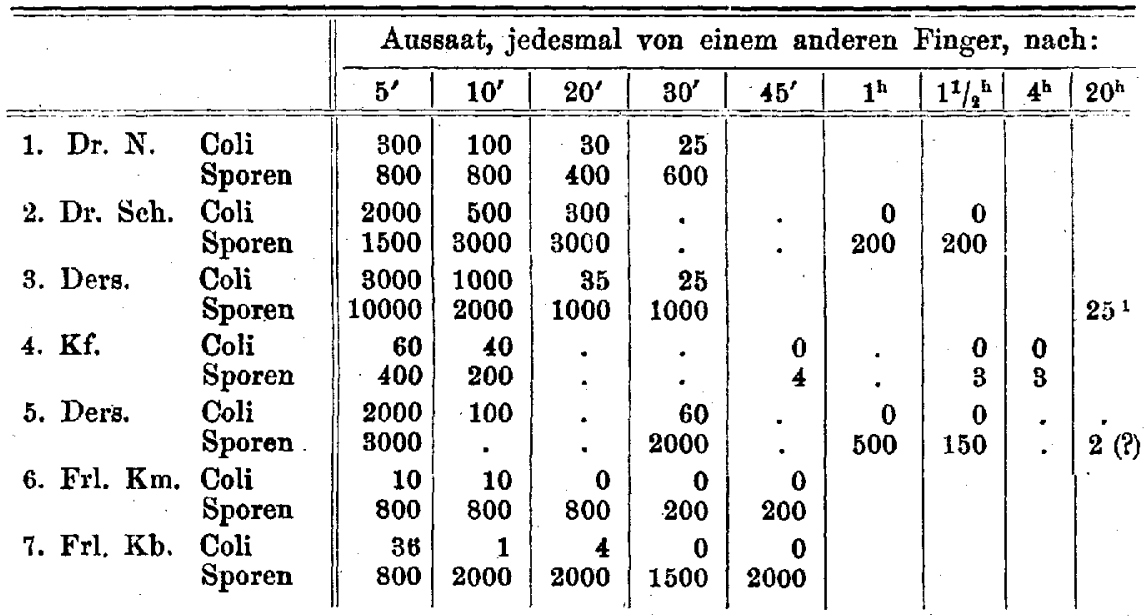

Versuch 1 bis 3 sind an sicher sublimatfreien Händen gemacht, bei 6 und 7 ist eine Nachwirkung ron Sublimat anzunehmen, bei 4 und 5 nicht sicher auszuschlieBen.

In allen Fällen versehwanden die Sporen sehr viel langsamer als die Colibazillen. Daraus schließen wir, daß die Ursache der Selbstreinigung zum mindesten nicht ausschließlich in mechanischen Vorgängen $z u$ suchen ist, sondern $\mathrm{daB}$ eine bakterientötende Wirkung-der Haut dabei eine wesentliche Rolle spielt. Diese bakterizide Wirkung mag sich verschiedenen Bak-

1 Aussaat von der ganzen Hand. 
terienarten gegenüber in verschiedener Weise äußern. Wir dürfen aber wohl als sicher annehmen, dəß die Bazillen der Typhus-Paratyphusgruppe dabei nicht widerstandsfähiger sein werden, als die Colibazillen. Daß Ruhrbazillen und Vibrionen dabei noch stärker abgetötet werden als unser Colistamm, zeigen die beiden folgenden Versuche (s. Tabelle 42 und 43).

\section{Tabelle 42.}

Selbstreinjgungsversuch nach Infektion mit einem Gemisch aus Coli und Y-Ruhrbazillen an sicher sublimatfreien Händen.

Je eine Agarkultur von Coli und Ruhr wird in 5 cem abgeschwemmt und $1 \mathrm{ccm}$ der Ruhrabscliwemmung zusammen mit 1 Tropfen der Coliabschwemmung in $10 \mathrm{~cm}$ verdünnter Bouillon gebracht. 1/10 Millionstel Tropfen ergibt bei Aussaat in Drigalskiagar 5 Colikolonien und $\mathbf{3 6}$ Y-Kolonien. Infektion: 3 Tropfen der etwa 1: 1000 verdünnten Mischung werden auf die Fingerspitzen beider Hände verrieben. Nach versehiedenen Zeiten wird je 1 Finger geprüft. (Auspressen in flüssigem Drigalskiagar.)

\begin{tabular}{|c|c|c|c|}
\hline $\begin{array}{l}\text { Prüfung } \\
\text { des Fingers }\end{array}$ & $\begin{array}{c}\text { Zeit nach der } \\
\text { Antrocknung }\end{array}$ & Coli - Kolonien & Y-Ruhr-Kolonien \\
\hline 5. & sofort & $\begin{array}{l}250 \\
500\end{array}$ & $\begin{array}{c}250 \\
500\end{array}$ \\
\hline 4. & $5^{\prime}$ dinach & $\begin{array}{r}1200 \\
400\end{array}$ & $\begin{array}{r}2800 \\
600\end{array}$ \\
\hline 3. & $10^{\prime} \quad \eta$ & $\begin{array}{l}30 \\
15\end{array}$ & $\begin{array}{l}\mathbf{7 0} \\
\mathbf{2 5}\end{array}$ \\
\hline 2. & $15^{\prime}$ & $\begin{array}{l}\mathrm{l} . \\
\mathrm{l} .\end{array}$ & $\begin{array}{r}11 \\
3\end{array}$ \\
\hline 1. & $20^{\prime} \quad$ & $\begin{array}{r}2 \\
30\end{array}$ & $\begin{array}{r}0 \\
120\end{array}$ \\
\hline ganze Hand & $30^{\prime}$ & $\begin{array}{cc}\text { r. } & \text { reichlich } \\
\text { 1. } & 20\end{array}$ & $\begin{array}{r}10 \\
150\end{array}$ \\
\hline
\end{tabular}

Anders können sich aber dic Streptokokken und Staphylokokken verhalten; die für den Chirurgen in Betracht kommen. Wir möchton daher aus unseren Versuchen keinen SchluB auf das spontane Verschwinden dieser Koime und auf die Karenzzcit ziehen, die ein Operateur oder Geburtshelfer nach der Beriihrung mit Wundinfektionserregern innehalten. mu $B$, um so weniger, als diese Keime den normalen Bewohnern der Haut ja sehr nahestehen. Colibazillen sind dagegen ebenso wie die Sporenbildner für die menschliche Háut fremde Keime; sie können sich augenscheinlich in der gesunden Haut unter keinen Umständen dauernd halten und vermehren. Das ist ja von vornherein zu erwarten, $d a$ sich sonst natürlich Colibazillen dauernd an jeder Hand finden müßten, was bekanntlich nicht der Fall jst. 


\section{Tàbelle 43 .}

Selbstreinigungsversuch mit Bact. coli und Vibriogemisch.

Schwache Infektion. Von einem Gemisch einer Abschwemmung einer Coli- und einer Vibrionenkultur werden 3 Tropfen anf beide Hände verrieben.

Versuchsperson $\mathrm{K}$.

\begin{tabular}{|c|c|c|c|}
\hline \multirow{2}{*}{$\begin{array}{c}\text { Prüfung } \\
\text { des Fingers }\end{array}$} & \multirow{2}{*}{$\begin{array}{c}\text { nach } \\
\text { Antrocknen }\end{array}$} & \multicolumn{2}{|c|}{ Keimabgabe } \\
\hline & & Coli-Kolonien & Vibrionen-Kolonien \\
\hline 1. & sofort & $\begin{array}{l}\text { r. } \quad 3000 \\
\text { l. } \quad 3000\end{array}$ & $\begin{array}{l}\text { neben den zahlreichen Coli } \\
\text { nicht gut erkennbar }\end{array}$ \\
\hline 2. & $5^{\prime}$ & $\begin{array}{ll}\text { r. } & 2 \\
\text { l. } & 0\end{array}$ & $\begin{array}{l}0 \\
0\end{array}$ \\
\hline 3. & $10^{\prime}$ & r. & $\begin{array}{l}0 \\
0\end{array}$ \\
\hline 4. & $20^{\prime}$ & $\begin{array}{r}100 \\
1\end{array}$ & $\begin{array}{r}20 \\
0\end{array}$ \\
\hline$\check{b}$ & $30^{\prime}$ & $\begin{array}{cc}\text { r. } & 0 \\
\text { l. } & 14 \\
\text { ehsperson } & B .\end{array}$ & $\begin{array}{l}0 \\
0\end{array}$ \\
\hline 1. & Antrocknen & $\begin{array}{ll}\text { r. } & \mathbf{2 0 0 0} \\
\text { l. } & \mathbf{2 5 0 0}\end{array}$ & $\begin{array}{l}? \\
?\end{array}$ \\
\hline 2. & $5^{\prime}$ & $\begin{array}{lr}\text { r. } & 1000 \\
\text { l. } & 120\end{array}$ & $\begin{array}{l}? \\
?\end{array}$ \\
\hline 3. & $10^{\prime}$ & $\begin{array}{l}50 \\
20\end{array}$ & $\begin{array}{r}10 \\
3\end{array}$ \\
\hline 4. & $20^{\prime}$ & $\begin{array}{l}30 \\
20\end{array}$ & $\begin{array}{l}3 \\
0\end{array}$ \\
\hline 5. & $30^{r}$ & $\begin{array}{l}30 \\
20\end{array}$ & $\begin{array}{l}0 \\
0\end{array}$ \\
\hline
\end{tabular}

\section{XI. Über die Bedeutung der einfachen Reinlichkeitsmaßnahmen für die Seuchenbekämpfung.}

Wir möchten zum Schlusse nochmals auf dic Bedeutung der einfachen ReinlichkeitsmaBnahmen zur Verhütung von Kontaktinfektionen zurückkommen. Das einfache Händewaschen wirkt gewiß recht unvollkommen, und die besonders von Flügge betonten Bedenken wegen der Möglichkeit einer Verstreuung von Kejmen sind an sich durchaus berechtigt. Schon Börnstein hat aber hervorgehoben, daß die auf den Fußboden, die Kleider, das Handtuch und in das Waschwasser gelangten Infektionserreger doch lange nicht so gefährlich sind, wie die auf der menschlichen Hand befindlichen, und die praktische Erfahrung bestätigt täglich den großen Einfluß gewöhnlicher Reinlichkeitsmaßnalımen. Ge wiß haben einfaches Händewaschen und Gebrauch von Klosettpapicr bisher weit mehr Ansteckungen verhütet und werden auch in Zukunft mehr verhüten, als alle Desinfizientien. 
Angesichts der starken spontanen Keimabnahme, die wir in den vorstehenden Versuchen regelmäßig sahen, kann man die Frage aufwerfen, ob es denn nicht vielleicht auch ebensogut ist, sich auf die Selbstreinigung als auf die Wirkung des Waschens zu verlassen; möglicherweise könnte ja auch das Waschen durch Verdünnung der Hautsekrete die Selbstreinigung verzögern, Nun ist allerdings der Erfolg der Selbstreinigung, so iiberraschend er an sich ist, zahlenmäßig denn doch nicht mit der Wirkung der Keimbeseitigung durch Waschen zu vergleichen; immerhin erschien es zweckmäßig, einige vergleichende Versuche darüber zu machen. Wir haben daher bei einer Versuchsperson beide Hände zu gleicher Zeit infiziert und darauf die eine mit Seife gebürstet, während die andere sich selbst überlassen wurde; in zwej Versuchen wurde der Keimgehalt nach 5 Minuten, in weiteren drei nach einer halben Stunde geprïft. In allen Fällen waren die Keimzahlen an der gewaschenen Hand außerordentlich viel kleiner; auch in der durch das Waschen aufgeweichten Haut gehen also die noch übrigbleibenden Keime unter dem Einfluß der Selbstreinigung schnell zugrunde.

Tabelle 44 .

Béide Hände werden in gleicher Weise infuziert. Sofort nach der Antrocknung wird die Infektion je eines Tïngers an jeder Hand geprüft. Die hierbei erzielte Keimabgabe ist, als Ausgangsinfektiou der ganzen Hand mit 5 multipliziert, in Klammern gesetzt. Die linke Hand wird 1 Min. lang mit Seife und steriler Bürste in flieBendem Wasser gewaschen, nachher mit sterilem Tuche getrocknet. Nach $5 \mathrm{bzw}$. 30 Min. wird die Keimabgabe der gewasehenen (linken) und der ungewasehenen(rechten) Hand geprüft.

A. Keimentnahme nach 5 Minuten.

Dr. Sch. (sublimatfreie Hände).

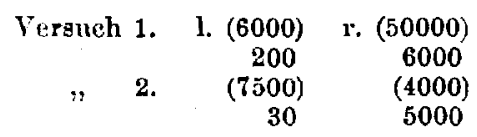

B. Keimentnahme nach 30 Minuten. Versuch 8. $\quad(6000) \quad(10000)$

$\begin{array}{rrrr} & & 2 & 2000 \\ & 4 . & (5000) & (10000) \\ & & 3 & 200 \\ & 5 . & (15000) & (20000) \\ & & 1 & 5000\end{array}$

Hiernach wird also der Erfolg des Waschens durch die Wirkung der Selbstreinigung in glücklichster Weise vervollständigt. Dabei trifft, was praktisch sehr bedeutsam ist, die Sclbstreinigung zunächst offenbar gerade die tiefliegenden Keime, die der Waschung stets und häufig auch der Desinfektion entgehen.

Die Wichtigkeit der Seifenwaschung zur Verhütung von Kontaktinfektionen erscheint hiernach auch experimentell gerechtfertigt und es bleibt nur übrig, diese Erkenntnis allgemein nutzbar zu machen: Es sei in dieser Beziehung auf die folgenden Ausführungen von Neufeld (Seuchenentstehung und Seuchenbekämpfung, Berlin 1914, S. 60-61) hingewiesen : „Wemn man es dahin bringen könnte, daß die Bevölkerung sich allgemein daran gewöhnt, nach Benutzung des Klosetts sowie vor jeder Mạhzeit 
sich die Hände zu waschen, so würde damit zweifellos eine überaus große Zahl von thertragungen nicht nur des, Typhus, sondern auch der anderen ansteckenden Darmerkrankungen vermieden werden. Es wäre dringend zi1 wuinschen, daß in den Schulen, insbesondere auch in den Volksschulen, allgemein hierauf hingewiesen wird, und daB die Kinder zur Einhaltung dieser ReinlichkeitsmaBnahmen erzogen werden, die ihnen dann später als selbstverständlich erscheinen werden. Auch in der Armee wäre die gleiche Art der Erziehung zur Reinlichkeit möglich und erwünscht. In dieser Beziehung sind uns die Amerikaner voraus: in den Vereinigten Staaten ist durch Armeebefehl angeordnet, daß jeder Soldat sich nach Benutzung des Klosetts und jedesmal vor dem Essen die Hände mit Seife zu waschen hat. Dies sollte in unserer Armee Nachahmung finden. Es würde nicht nur die Übertragung von Krankheiten im Heere selbst verringern, sondern vor allem würden die Leute, einmal an solche Reinlichkeit gewöhnt, vielfach dieselbe auch suäter beibehalten und zur Verbreitung hygienischer Sitten im Volke beitragen. Es wäre wohl eines Versuches wert, was man durch diese hygienische Belehrung an zwei wichtigen Stellen, nämlich in der Sehule und im Heere, für die hygienisehe Erziehung unseres Volkes. erreichen könnte."

Seitdem ist im Heere die Belehrung der Mannschaften und die Ausgabe von Klosettpapier wohl allgemein durchgeführt worden und gelegentlich des Auftretens der. Ruhr im Sommer 1917 sind anch in manchen Schulen entsprechende Belehrungen angeordnet worden; es wäre zu wünschen, daß diese Maßnahmen im Frieden beibehalten und weiter ausgebaut wïrden, zumal wir als Folge des Krieges wohl noch längere Zeit hindurch mit einem vermehrten Auftreten von Typhus und Ruhr und vor allem mit einer großen Zahl von Bazillenträgern rechnen müssen, die dauernd unter der Bevölkerıng leben werden. Halten wir uns neben der Wirkung des Waschens und der Selbstreinigung die vorher mitgeteilten Ergebnisse vor Augen, wonach von stark infjzierten Händen auf eine reine Hand (und ebenso auf andere trockene oder annähernd trockene Objekte) nur ein sehr kleiner Bruchteil der daran haftenden Keime ïbergeht, von schwach infizierten Händen in der Regel aber gar'keine, so wird es verständlich, daß es fast immer ganz grobe Unsauberkeiten sind, die zu den gewöhnlichen Kontaktinfektionen führen. Dem sollte u. E. sowohl in den von den Behörden erlassenen Belehrungen als auch in den Desinfektionsanweisungen mehr als bisher Rechnung getragen werden. Dann würde sich eine Reihe von Maßnahmen erübrigen, z. B. solche, die-sich gegen die vereinzelten infektiösen Keime richten, die vielleicht ausnahmsweise einmal an Möbeln und Wänden, an Büchern und Spielsachen, an Kämmen und Bürsten sitzen 
mögen, und von denen wohl kaum jemals Infektionen ausgehen. Läßt man alle diese überflüssigen Dinge aus den Anweisungen und Belehrungen weg, so gewinnt man Raum, um mit Nachdruck auf das hinzuweisen, was wirkl ch wichtig ist, vor allem auf die Bedeutung infizierter Hände, die bisher bisweilen ganz nebenher, bisweilen auch gar nicht eigens erwähnt werden. Da.B gewisse Verrichtungen in der Wirtschaft -- Anrichten von Salaten und anderen Speisen, die nachher nicht noch gekocht werden, auch von Hackfleisch mit den Fingern, Melken und Hantieren mit Milch - insofern eine besondere Stellung einnehmen, als dabei auch schwach infizierte Hände leicht Infektionen ermitteln, wurde oben schon hervorgehoben; auch diese Verhältnisse würden wohl zweckmäßig bei künftigen Bolehrungen mehr als bisher zu berücksichtigen sein. Wir würden in der Bekämpfung ler Seuchen, insbesondere des Typhus und der Ruhr, den wesentlichsten Fortschritt erzielen, wenn es gelänge, die Bevölkerung allgemein darüber aufzuklären - was jetzt den meisten Gebildeten nicht recht bekannt ist - , auf wie einfache Weise bei diesen Krankheiten die Ansteckung in der Regel erfolgt und auf wie einfache Weise der größte Teil dieser Ansteckungen $\mathrm{zu}$ verhüten ist. 
184 O. Schibman und Hans Land Ju: Uber Händedesinfektjon usw.

\section{Literaturverzeichnis.}

1. Andrewes und Orton, Zentralbl. f. Bakteriol. 1904. Bd. XXXV. s. 645.

2. Baracz, Wien. klin.Woch. 1904. Nr. 13 u. Zentralbl.f. Chir. 1917. Nr. 21.

3. Bechbold, Hünehener med. Wochenschrift. 1914. S. 1929 und diese Zeitsehrift. Bd. LXXVII. S. 436.

4. Börnstein, diese Zeitsehrift. Bd. LXXIX. S. 145.

5. Flügge, ebenda. Bd. L. S. 233.

6. Gocht, Deutsche med. Wochenschrift. 1916. Nr.11. S. 1262.

7. Huntem ïller und Eckard, Berliner klin. Wochenschrift. 1914. Nr. 32.

8. Hübler, Deutsche med. Woohenschrift. 1915. S. 195.

9. Jötten, ebenda. 1915. Nr. 47. S. 1388.

10. Landau, Berliner klin. Wochensehrift. 1918. S. 670.

11. Neufeld, Deutsche med. Wochenschrift. 1918. Nr, 37.

12. Neufeld u. Karlbaum, Deutsehe med. Wochenschrift. 1918. Nr. 5.

13. Neufeld und Schiemann, diese Zeitschrift. Bd. LXXXV. S. 193.

14. Ostermann, Diese Zeitsehrift. Bd. XL.

15. Reichert, Aratliclee Rudschau. 1917. Nr. 18.

16. Schottelins, Archiv für Hygiene. Bd. LXXXII. S.77.

17. Speck, diese Zeitsehrift. Bd. L. S. 502.

18. Unna, Hamburger Ärate-Korresp. 1916. Nr. 50.

19. Vas, Intern. Hygienekongreß. London 1913.

20. Weichardt u. Haussner, Ergebnisse der inneren Medizin und Kinderheilkunde. 1913. Bd. X. S. 812. 